\title{
Increased Microglial Activity, Impaired Adult Hippocampal Neurogenesis, and Depressive-like Behavior in Microglial VPS35-Depleted Mice
}

\author{
- Joanna Ruth Appel, ${ }^{1}$ Shiyang Ye, ${ }^{1,2,3}$ Fulei Tang, ${ }^{1}$ Dong Sun, ${ }^{1,2}{ }^{-}$Hongsheng Zhang, ${ }^{1,2}{ }^{-}$Lin Mei, ${ }^{1,2}$ \\ and $1 D$ Wen-Cheng Xiong ${ }^{1,2}$ \\ ${ }^{1}$ Department of Neuroscience and Regenerative Medicine, Medical College of Georgia at Augusta University, Augusta, Georgia 30912, ${ }^{2}$ Department of \\ Neurosciences, School of Medicine, Case Western Reserve University, Cleveland, Ohio 44106, and ${ }^{3}$ Molecular Biology Center, State Key Laboratory of \\ Trauma, Burn, and Combined Injury, Research Institute of Surgery and Daping Hospital, Third Military Medical University, Chongqing, 400042 China
}

Vacuolar sorting protein 35 (VPS35) is a critical component of retromer, which is essential for selective endosome-to-Golgi retrieval of membrane proteins. VPS35 deficiency is implicated in neurodegenerative disease pathology, including Alzheimer's disease (AD). However, exactly how VPS35 loss promotes AD pathogenesis remains largely unclear. VPS35 is expressed in various types of cells in the brain, including neurons and microglia. Whereas neuronal VPS35 plays a critical role in preventing neurodegeneration, the role of microglial VPS35 is largely unknown. Here we provide evidence for microglial VPS35's function in preventing microglial activation and promoting adult hippocampal neurogenesis. VPS35 is expressed in microglia in various regions of the mouse brain, with a unique distribution pattern in a brain region-dependent manner. Conditional knocking out of VPS35 in microglia of male mice results in regionally increased microglial density and activity in the subgranular zone of the hippocampal dentate gyrus (DG), accompanied by elevated neural progenitor proliferation, but decreased neuronal differentiation. Additionally, newborn neurons in the mutant DG show impaired dendritic morphology and reduced dendritic spine density. When examining the behavioral phenotypes of these animals, microglial VPS3Sdepleted mice display depression-like behavior and impairment in long-term recognition memory. At the cellular level, VPS35-depleted microglia have grossly enlarged vacuolar structures with increased phagocytic activity toward postsynaptic marker PSD95, which may underlie the loss of dendritic spines observed in the mutant DG. Together, these findings identify an important role of microglial VPS35 in suppressing microglial activation and promoting hippocampal neurogenesis, which are both processes involved in $\mathrm{AD}$ pathogenesis.

Key words: Alzheimer's disease; hippocampus; microglia; neurogenesis; retromer; VPS35

\section{Significance Statement}

The findings presented here provide the first in vivo evidence that Vacuolar sorting protein 35 (VPS35)/retromer is essential for regulating microglial function and that when microglial retromer mechanics are disrupted, the surrounding brain tissue can be affected in a neurodegenerative manner. These findings present a novel, microglial-specific role of VPS35 and raise multiple questions regarding the mechanisms underlying our observations. These findings also have myriad implications for the field of retromer research and the role of retromer dysfunction in neurodegenerative pathophysiology. Furthermore, they implicate a pivotal role of microglia in the regulation of adult hippocampal neurogenesis and the survival/integration of newborn neurons in the adult hippocampus.

\section{Introduction}

Alzheimer's disease $(\mathrm{AD})$ is a severely debilitating neurodegenerative condition characterized by abnormal accumulation of neurotoxic amyloid $\beta$ peptides and tau protein, accompanied by severe hippocampal neuronal loss. While AD pathophysiology

\footnotetext{
Received Dec. 23, 2017; revised May 15, 2018; accepted May 21, 2018.

Author contributions: J.R.A. and W.-C.X. designed research; J.R.A., S.Y., F.T., and D.S. performed research; H.Z. and L.M. contributed unpublished reagents/analytic tools; J.R.A., S.Y., F.T., D.S., and W.-C.X. analyzed data; W.-C.X. wrote the paper.

This work was supported by grant from the National Institutes of Health (AG045781 to W.-C.X.).

The authors declare no competing financial interests.
}

has fundamentally been identified, the underlying mechanisms that contribute to initial disease onset and perpetuate disease progression remain open to speculation.

A multitude of genes have been identified as susceptibility genes in $\mathrm{AD}$ pathology, including vacuolar protein sorting-associated protein 35 (VPS35; Small et al., 2005). VPS35 is an essential member of

Correspondence should be addressed to Wen-Cheng Xiong, Department of Neuroscience, School of Med icine, Case Western Reserve University, 10900 Euclid Avenue, Cleveland, Ohio 44106. E-mail: Wen-Cheng.Xiong@case.edu.

DOI:10.1523/JNEUROSCI.3621-17.2018

Copyright $\odot 2018$ the authors $\quad 0270-6474 / 18 / 385949-20 \$ 15.00 / 0$ 
the cargo recognition module of retromer (Nothwehr et al., 1999; Hierro et al., 2007), a multimeric protein complex that facilitates intracellular retrograde trafficking of select transmembrane proteins (Seaman et al., 1998). Molecular participants in the neurodegenerative cascade have been identified as retromer cargos, and when retromer is made dysfunctional, functional activity of retromer cargos can be impaired or altered, affecting a multitude of pathological consequences (Small and Petsko, 2015).

VPS35 is a ubiquitously expressed protein, with expression level varying by cell type (e.g., neurons and glial cells) and region throughout the CNS (Wen et al., 2011; Wang et al., 2012; Lucin et al., 2013; Liu et al., 2014). Much attention has been given to the role of neuronal VPS35, where VPS35/retromer has been shown to participate in the mediation of crucial cellular processes, such as the regulation of amyloid precursor protein trafficking and proteolytic processing (Nielsen et al., 2007; Muhammad et al., 2008; Wen et al., 2011; Ueda et al., 2016), the trafficking of neurotransmitter receptors (Munsie et al., 2015; Tian et al., 2015), mitochondrial fusion/fission dynamics (Tang et al., 2015b; Wang et al., 2016), and the establishment and regulation of neuronal function (Prasad and Clark, 2006; Bonifacino, 2014; Vergés, 2016). Little is known regarding the function of microglial VPS35 in the pathogenesis of $\mathrm{AD}$.

Microglial VPS35 is downregulated in the brains of AD patients (Lucin et al., 2013). In vitro studies have shown that microglial VPS35 deficiency can reduce the presentation of microglial phagocytic receptors at the cellular membrane, impairing the phagocytic capacity of microglia (Lucin et al., 2013). More recently, in vitro deletion of VPS 35 from the BV2 microglial cell line has been shown to exacerbate the microglial inflammatory response (Yin et al., 2016). While these observations implicate microglial VPS35 in AD pathogenesis, exactly how the cellular functions of microglia are affected by VPS35 deficiency and how VPS35deficient microglia might affect surrounding neural tissue in vivo remain poorly understood.

Here, we used a Cre-lox inducible mouse model of microglial VPS35 depletion (VPS35 ${ }^{\mathrm{CX} 3 \mathrm{CR} 1}$ ) and found a regional-specific increase in hippocampal microglial density in conjunction with exacerbated hippocampal microglial activity. Hippocampal phenotype analysis of the adult VPS3 $5^{\text {CX3CR1 }}$ mouse revealed aberrant neurogenesis and a neurodegenerative-like deficit of newborn hippocampal DG neurons. VPS35 ${ }^{\text {CX3CR1 }}$ mice also exhibited a depressive behavioral phenotype and impaired long-term recognition memory. In vitro microglial-neuronal cocultures revealed, along with enlarged vacuolar structures, exacerbated microglial phagocytic activity in VPS35-depleted microglia. In aggregate, our results suggest that microglial VPS35 loss of function contributes to upregulated microglial activity in vivo in a manner that may affect neurodegeneration more severely in the hippocampus, contributing to $\mathrm{AD}$ relevant pathology and implicating a novel microglial-specific function of VPS35 in maintaining hippocampal homeostasis and adult neurogenesis.

\section{Materials and Methods}

\section{Animals}

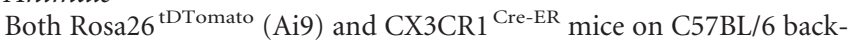
ground were purchased from the Jackson Laboratory (stock no. 00790, RRID:IMSR_JAX:007905, and stock no. 021160, RRID:IMSR_JAX: 021160 , respectively). VPS35 $5^{\text {flox/flox }}$ mice, generated as described previously (Tang et al., 2015a), were backcrossed onto C57BL/6J background for $>6$ generations. VPS35 $5^{\text {flox/flox }}$ mice were crossed with CX3CR 1 Cre-ER mice to generate VPS $35^{\text {flox/flox }}$ :CX3CR $1^{\text {Cre-ER/+ }}$ mice (labeled in this

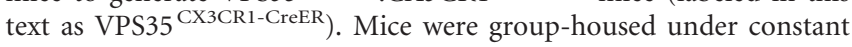

$12 \mathrm{~h}$ light/dark conditions and fed a diet of standard rodent chow. All experimental procedures were approved by the Animal Subjects Committee at Augusta University and Case Western Reserve University according to U.S. National Institutes of Health guidelines.

\section{Experimental design and statistical analysis}

At postnatal day (P) 15, VPS35 ${ }^{\text {CX3CR1-CreER }}$ mice were administered 75 $\mathrm{mg} / \mathrm{kg}$ of tamoxifen (Sigma-Aldrich) dissolved in corn oil (Sigma-Aldrich) intraperitoneally daily for 5 consecutive days to induce Cre recombination via the CX3CR1 promoter, resulting in VPS $35^{\mathrm{CX} 3 \mathrm{CR} 1 /+}$ mice (labeled in this text as VPS35 ${ }^{\text {CX3CR1 }}$ ). Unless otherwise noted in the text, data reported are those recorded from age-matched littermate control mice that were vehicle-

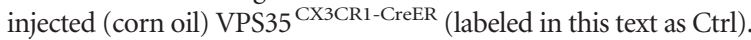

All experimental results were also confirmed in tamoxifen-injected controls (CX3CR $1^{\text {Cre-ER/+ }}$ or VPS3 $5^{\text {flox/flox }}$ mice) to eliminate any potential effects of tamoxifen alone upon our observations. Male mice were used for all in vivo experiments to exclude any potential differential effects of the female estrous cycle.

The number of animals varied per experiment and is noted in the corresponding figure legend. For immunohistochemical analyses, $a \geq 7$ brain sections/animal were evaluated ( $40 \mu \mathrm{m}$ sections unless otherwise noted; every fourth or sixth section was used). Number of cells analyzed varied by experiment and is indicated in the corresponding figure legend. Experimental details specific to behavioral testing are included in Behavior analyses below.

Statistical analyses were performed using Prism 5 (GraphPad Software). All values are expressed as mean \pm SEM. The test was considered significant when $p<0.05$. For all analyses, the following apply: ${ }^{*}$, significant $p<0.05$; ns, not significant $p>0.05$. Exact $p$ value for each analysis is indicated in the corresponding figure legend as well as the number of animals/cells used. Normally distributed data were analyzed by ANOVA followed by Bonferroni or Fisher's least significant difference post hoc tests as necessary. Student's $t$ test was used to compare pairs of means.

\section{5-bromo-2'-deoxyuridine labeling of dividing cells}

Every $3 \mathrm{~h}$ over a $12 \mathrm{~h}$ timespan, $50 \mathrm{mg} / \mathrm{kg}$ of bromodeoxyuridine (BrdU; EMD Millipore) in solution was administered, resulting in a total of four injections. Brain tissue was removed either $24 \mathrm{~h}$ or $7 \mathrm{~d}$ following the initial BrdU injection, as indicated in the text.

\section{Stereotaxic injection of retroviral vector}

CAG-GFP retrovirus was generated in which the expression of enhanced GFP is driven by the compound promoter CAG (which contains the cytomegalovirus enhancer chicken $\beta$-actin promoter and a large synthetic intron). Retrovirus was produced as described previously by Zhao et al. (2006). Resulting titer was $\sim 3 \times 10^{8} \mathrm{cfu} / \mathrm{ml}$. Mice were placed under anesthesia (isoflurane; Sigma-Aldrich, catalog \#792632) and stereotaxic injections of $2 \mu \mathrm{l}$ of CAG-GFP retrovirus were placed into the right dentate gyrus (DG) of mice immediately following tamoxifen or corn oil treatment (at P20). Stereotaxic coordinates of injection were as follows: anteroposterior, $-2.0 \mathrm{~mm}$; lateral, $1.5 \mathrm{~mm}$; ventral, $1.7 \mathrm{~mm}$ relative to bregma. One month following administration of the retrovirus, mice were perfused with PBS, followed by perfusion with $4 \%$ PFA. Brain tissue was removed and fixed overnight in $2 \%$ PFA and $100 \mu \mathrm{m}$ sections were cut by the Leica vibratome system for immunohistochemical analysis.

\section{Behavior analyses}

Groups of male mice were prepared for behavioral analysis by daily handling by the investigator 2 weeks before behavioral assessment. Behavioral analyses were performed in a dedicated behavioral facility. Animals were relocated to the facility daily $\geq 1 \mathrm{~h}$ before the onset of testing to allow for acclimation. All behavioral assessments were initiated $\leq 2 \mathrm{~h}$ before the onset of the animals' active cycle to ensure alertness. Mice had $\geq 2 \mathrm{~d}$ of resting time between tests to decrease carryover effects from prior tests. The order of tests occurred as follows: open-field test, Y-maze, novel-object recognition, tail-suspension test, forced swim test, sucrose preference. Arenas were cleaned with $70 \%$ ethanol between each animal. Unless otherwise noted, all behavioral trials were recorded on digital video and manually assessed in a blind manner. 
Open-field test. The open-field test was performed in an arena measuring $50 \mathrm{~cm}^{2}$. Mice, placed in the center of the open field, were allowed to explore the arena undisturbed for $10 \mathrm{~min}$. Video analysis and data acquisition were obtained with Noldus tracking software (EthoVision XT, 7.0) to analyze total distance and mean velocity.

$Y$-maze. Spatial memory was analyzed with the Y-maze test, conducted using a symmetrical Y-maze with 35-cm-long arms and 8-cm-tall walls. Each arm contained differently shaped markers upon the opposing face. For each trial, the mouse was placed in the starting arm for $30 \mathrm{~s}$, after which the animal was allowed to explore the maze. Upon entering an arm, the animal was blocked off within that arm for $60 \mathrm{~s}$ and then returned to the starting arm for the next trial. Animals were subjected to five trials, with each arm entry manually recorded by the investigator. Percentage alternation was reported as number of trials in which the animal alternated arm entry divided by total number of trials.

Novel-object recognition. Recognition memory was assessed using the novel-object recognition paradigm. Each animal was placed in a $25 \times 50$ $\mathrm{cm}$ arena, with objects placed at each end of the arena. All objects used were fixed on a stationary base. Location in the arena varied pseudorandomly across trials. At time-point zero, animals were individually placed into arenas containing two identical objects on opposing sides of the cage. Following $10 \mathrm{~min}$ of investigation, animals were removed and returned to home cages. After each time point, one object was replaced with a novel object and animals were allowed 5 min of investigation. All trials were videotaped and exploratory intervals were manually scored by a blind observer. Investigation of an object was defined as time spent with nose directed at the object at a distance of $\leq 3 \mathrm{~cm}$ from the object for the duration of the recording. Recognition index is reported as time spent investigating novel object divided by the sum of the time spent investigating novel object plus time spent investigating familiar object (total time of exploratory behavior).

Tail-suspension test. The tail-suspension test was performed using a specially manufactured tail-suspension box $(55 \times 60 \mathrm{~cm})$ sectioned into four $15 \mathrm{~cm}$ compartments. Within each compartment, a small, plastic bar hung from the base. The tail of each animal was taped to this bar and animals were suspended for $6 \mathrm{~min}$. Percentage immobility is reported as time spent immobile divided by total time, where immobility was gauged as a lack of escape-driven activity.

Forced-swim test. Clear, plastic cylinders, each with a radius of $30 \mathrm{~cm}$, were filled with room-temperature water and partitioned so that animals were unable to observe animals in the neighboring apparatus. Mice were placed into the water for $6 \mathrm{~min}$, after which they were removed, dried, and returned to a cage warmed on a heating mat. The last 4 min of testing time were scored and percentage immobility was reported as time spent immobile divided by total time scored $(4 \mathrm{~min})$ where mobility was defined as "any movement other than those necessary to balance the body and keep the head above the water" (Cryan et al., 2002).

Sucrose-preference testing. Mice were individually housed in cages containing two dual bearing sipper tubes filled with water for $3 \mathrm{~d}$ to habituate mice to the presence of two water sources. Following the acclimation period, one tube was filled with $2 \%$ sucrose while the other contained water only. Tube levels were measured daily for $4 \mathrm{~d}$ and rotated to prevent location bias. Sucrose preference is reported as a percentage of the volume of sucrose intake over the total volume of fluid intake averaged over the testing period.

\section{Histology, immunohistochemistry, and immunofluorescence}

For immunostaining analysis, male mice were perfused with PBS followed by perfusion with $4 \%$ PFA. Brain tissue was removed and fixed overnight in $2 \%$ PFA. Forty micrometer sections were cut using the Leica vibratome system and blocked with blocking solution containing $0.1 \%$ Triton X-100 for permeabilization. Before blocking, sections to be analyzed for BrdU immunostaining were first incubated in $2 \mathrm{~N} \mathrm{HCl}$ at room temperature for $1 \mathrm{~h}$, followed by one $5 \mathrm{~min}$ rinse and one $10 \mathrm{~min}$ rinse with $0.1 \mathrm{~m}$ sodium borate buffer, $\mathrm{pH} 8.5$. Sections were incubated at $4^{\circ} \mathrm{C}$ overnight with primary antibody as follows: GFP (Aves Labs, GFP-1020, RRID:AB_10000240; 1:1000), IBA1 (Abcam, ab5076, RRID:AB_2224402; 1:300), doublecortin (DCX; Santa Cruz Biotechnology, SC-8066, RRID: AB_2088494; 1:200), BrdU (Sigma-Aldrich, B-2531, RRID:AB_476793;
1:200), VPS35 (Abcam, ab10099, RRID:AB_296841; 1:150), CD16/32 (Abcam, ab24187, RRID:AB_2294040; 1:200), Ki67 (Dako, M724001-2, RRID:AB_2631211; 1:200), Olig2 (Abcam, ab33427, RRID:AB_776906; 1:500), Tuj1 (Covance, MMS-435P, RRID:AB_2313773; 1:750), Tmem119 (Abcam, ab209064, RRID:AB_2728083; 1:100). Sections were incubated for $1 \mathrm{~h}$ at room temperature the following day using the appropriate secondary antibody at 1:500 (Thermo Fisher Scientific, Alexa Fluor conjugates). Slides were mounted using Prolong Diamond Antifade mounting media with or without DAPI (Thermo Fisher Scientific) and confocal images were obtained using a Nikon A1R MP+ multiphoton confocal microscope with $20 \times$ or oil-immersion $60 \times$ objective with sequentialacquisition setting. Quantitative analyses were performed using ImageJ software as a measure of mean optical density.

\section{Stereological analysis of cellular density}

Stereological estimation for cell count density was obtained manually in a blind manner as follows. Regional images of every fourth section of brain tissue from each animal were obtained by Nikon NS Elements imaging software, large-image acquisition. Images were analyzed and total cell counts by regional area were obtained manually. Cellular density was calculated based upon total section volume (cells $\left./ \mathrm{mm}^{3}\right)$.

\section{Microglial morphological analysis}

Random images of GFP + cells in the region of interest were obtained using an oil-immersion $60 \times$ objective lens on a Nikon A1R MP + multiphoton confocal microscope.

\section{Calculation of microglial soma volume}

$\mathrm{Nd} 2$ files were converted into .ser files using Reconstruct software (https://synapseweb.clm.utexas.edu) and individual cell somas were traced at each step of the series. Only cell somas fully included within the section were included in this analysis. Each Reconstruct series was scaled to size and the volume of each object traced (i.e., total soma) was calculated by the software.

\section{Calculation of total process length}

Cells identified were those in which the cell soma was centered in the tissue section and all processes were included in the image stack. Using ImageJ, the image stack was merged and scaled before the threshold was applied. This image was loaded using the ImageJ plugin, NeuronJ, and the microglial processes were traced to enable calculation of total process length.

\section{Western blotting analysis}

Cells and tissue were homogenized in RIPA lysis buffer (50 mm Tris, 150 mM NaCl, 1 mm EDTA, $1 \%$ Triton X-100, 0.1\% SDS, and 0.5\% sodium deoxycholate) supplemented with protease inhibitors (Roche Applied Science). After a $20 \mathrm{~min}$ incubation on ice, protein extracts were clarified by centrifugation at $12,000 \times g$ for $20 \mathrm{~min}$ at $4^{\circ} \mathrm{C}$ and protein concentrations were determined by BCA Protein Assay Kit (Pierce Biotechnology). For Western blot analysis, $20-40 \mu \mathrm{g}$ of lysate per lane was separated by Bis-Tris SDS-PAGE gel. After transfer to nitrocellulose membranes, the membranes were immunoblotted with the following antibodies: rabbit anti-VPS35 (1:10,000; gift from Dr. K.-W. Kim, Columbia University), IBA1 (1:10,000; Abcam, ab5076, RRID:AB_2224402), MHCII (1:10,000; Thermo Fisher Scientific, 14-5321, RRID:AB_467560), IL-6 (1:500; Santa Cruz Biotechnology, sc-1265, RRID:AB_2127470). For semiquantitative analysis, protein bands were detected by the Odyssey Infrared Imaging System (Li-Cor) and analyzed using ImageJ software.

\section{Isolation of microglia for protein analysis}

Microglial cell lysates were prepared from adult brain tissue following isolation with the Miltenyi Biotec MACS (magnetic activated cell sorting) cell separation system with minor modifications to the manufacturer's protocol. Briefly, brains from VPS35 ${ }^{\mathrm{CX} 3 \mathrm{CR} 1}$ mice or corn oil-treated controls were dissected and tissue was dissociated in DMEM (EMD Millipore) using the Neural Tissue Dissociation Kit-Postnatal (Miltenyi) with the gentleMACS Octo dissociator with heaters using program 37C_ABDK_1. The dissociated tissue was filtered through a $100 \mu \mathrm{m}$ mesh filter and rinsed with Dulbecco's PBS. Cellular debris were removed with Debris Removal Solution (Miltenyi). Microglia were isolated from the final single-cell suspension using the MACS technology with 

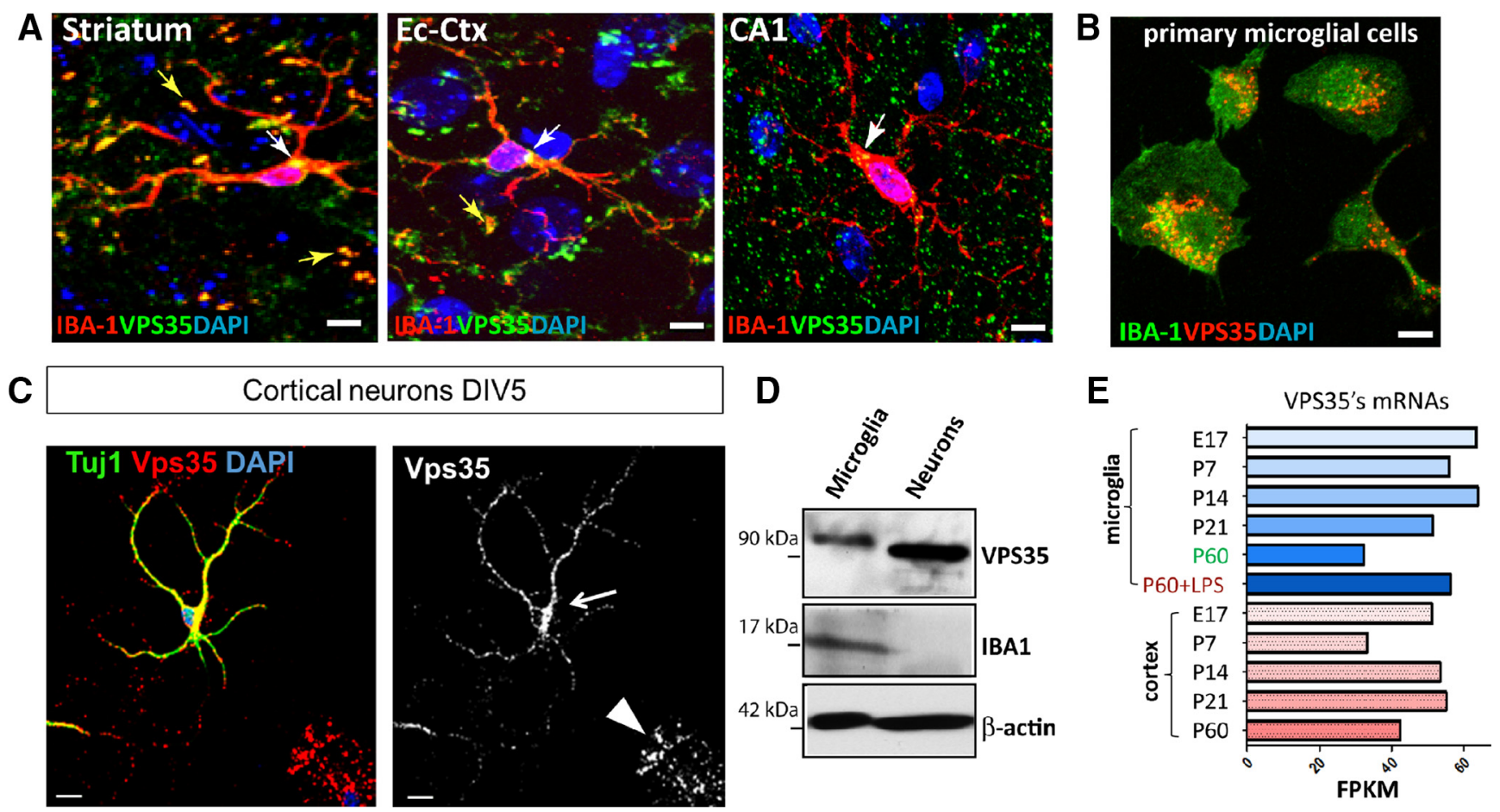

Figure 1. Microglial VPS35 expression. $\boldsymbol{A}$, Representative images of in vivo microglial VPS35 expression in various brain regions [CA1 (hippocampus), striatum, Ec-Ctx] as exhibited by IBA-1 coimmunofluorescence. Scale bar, $10 \mu \mathrm{m}$. B, Representative image of primary cultured microglial VPS35 expression by coimmunostaining analysis. Primary microglia cultures were obtained from C57BL/6J mice and immunostained with primary antibodies for IBA1 and VPS35. Scale bar, $10 \mu \mathrm{m}$. C, Representative image of primary cultured cortical neuronal VPS35 expression by coimmunostaining analysis. Cortical neuronal cultures were obtained from C57BL/6J mice and immunostained with primary antibodies for Tuj1 and VPS35. Arrow, Neuron; arrowhead, non-neuronal cell (likely a glial cell). Scale bar, $20 \mu \mathrm{m}$. D. Western blot analysis of microglial VPS35 expression. Soluble lysates from primary microglia and neuronal cultures from $557 \mathrm{BL} / 6 \mathrm{~J}$ mice were subjected to Western blot analysis. $\boldsymbol{E}$, VPS35 mRNA levels in microglia and cortex from mice at indicated age. Data were adapted from http://web.stanford.edu/group/barres_lab/brainseq2/brainseq2.html. FPKM, Fragments per kilobase of transcript per million mapped reads.

anti-cluster of differentiation molecule 11b (CD11b) MicroBeads (Miltenyi).

\section{Isolation of primary microglia}

Brain tissue from adult VPS35 ${ }^{\text {CX3CR1 }}$ mice or corn oil-treated controls was dissociated using the Miltenyi Neural Tissue Dissociation Kit as described above. Following MicroBead isolation, cells were counted and resuspended in microglia culture medium [DMEM, 10\% fetal bovine serum (Sigma-Aldrich), 1\% penicillin-streptomycin (Sigma-Aldrich) plus $10 \mathrm{ng} / \mathrm{ml}$ GM-CSF (Sigma-Aldrich)]. Cells were plated to poly-Dlysine (Sigma-Aldrich)-coated coverslips in a 24-well plate at a density of $1 \times 10^{5}$ cells suspended in $50 \mu \mathrm{l}$ of medium. Cells were allowed to rest 30 min at $37^{\circ} \mathrm{C}$, after which $450 \mu \mathrm{l}$ of medium was added to each well. Cells were maintained in $5 \% \mathrm{CO}_{2}$ incubator at $37^{\circ} \mathrm{C}$, replacing $50 \%$ of the culture medium every $24 \mathrm{~h}$. Primary cell cultures were used for experimental analyses following $7 \mathrm{~d}$ in vitro (DIV).

\section{Microglial-neuronal coculture and transfection}

Neuronal tissue was dissociated from cortices of P0 C57BL/6J mice using the Miltenyi Neural Tissue Dissociation Kit as described above, replacing DMEM with Neurobasal-A. Dissociated tissue was resuspended in neuronal growth medium (Neurobasal-A plus $1 \times$ B27, 2 mm GlutaMAX-1, and $1 \%$ penicillin/streptomycin) and plated onto poly-D-lysine (SigmaAldrich)-coated coverslips in a 12 -well plate at a density of $1 \times 10^{5}$ cells per well. Cells were maintained in $5 \% \mathrm{CO}_{2}$ incubator at $37^{\circ} \mathrm{C}$, replacing $50 \%$ of the growth medium every $24 \mathrm{~h}$. At $14 \mathrm{DIV}$, neurons were overlaid with primary microglia (isolated as described above and resuspended in neuronal growth medium) at density of $2 \times 10^{4}$ microglia/well (to obtain a 1:5 microglia/neuron ratio) and were cocultured for an additional 5 DIV. Cocultures were then fixed and stained for analysis.

Neuronal cultures obtained as described above were subjected to transient transfection with mCherry ( $\mathrm{mCh}$ ) construct at $4 \mathrm{DIV}$ using the calcium phosphate-mediated gene transfer method, as described previ- ously (Jiang and Chen, 2006; Zhu et al., 2007). At 7 DIV, transfected neurons were overlaid with primary microglia as described above for an additional 5 DIV. Cocultures were then fixed and stained for analysis.

\section{Results}

\section{Microglial VPS35 expression}

To investigate how VPS35 deficiency promotes the pathogenesis of neurodegenerative disorders, including $\mathrm{AD}$ and Parkinson's disease (PD), we first sought to determine the cell types that express VPS35. Coimmunofluorescence staining analysis in young-adult mouse brain sections showed abundant VPS35 expression not only in neurons (Fig. 1C) (both glutamatergic and dopaminergic neurons; Wen et al., 2011; Tang et al., 2015b; Wang et al., 2016), but also in IBA microglia in various brain regions, including the striatum, entorhinal cortex (Ec-Ctx), and hippocampus (Fig. 1A). Microglial VPS35 expression was further verified by the coimmunostaining analysis of VPS35 with IBA (ionized calcium binding adaptor) in primary cultured microglia (Fig. 1B) and by Western blot analysis of microglial cell lysates (Fig. 1D). Notice that a slightly higher molecular weight of microglial VPS35 than that of neuronal VPS35 was detected by Western blot analysis (Fig. 1D), suggesting a different isoform/ splice variant or a post-transcriptional modification of microglial VPS35 from that in neurons. Also notice that gene expression profiling studies of VPS35 in microglial cells and cortices of mice at various ages showed variable expression levels of microglial VPS35 throughout the murine lifespan (Fig. 1E), supporting the view for microglial VPS35 expression in both the developing and adult brain. Note that microglial VPS35 expression was higher in mice at the neonatal age (P7-P21) compared with that of mice at 


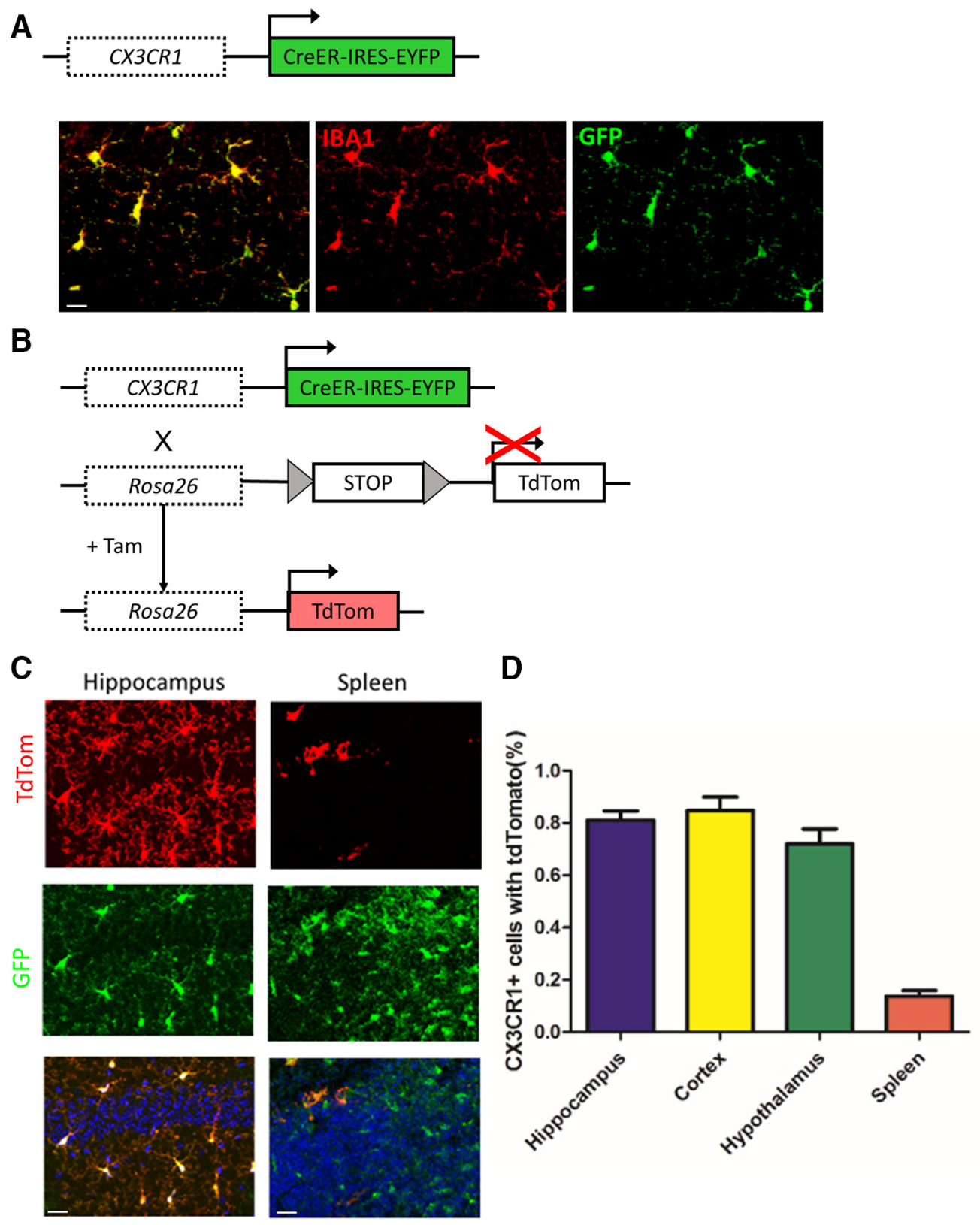

Figure 2. Characterization of microglial Cre activity in the $\mathrm{CX} 3 \mathrm{CR}^{\mathrm{Cre}-\mathrm{ER} /+}$ mouse. $A$, Microglia-specific Cre expression in the $\mathrm{CX} 3 \mathrm{CR} 1^{\text {Cre-ER/++ }}$ mouse line. Top, Schematic of the gene encoding

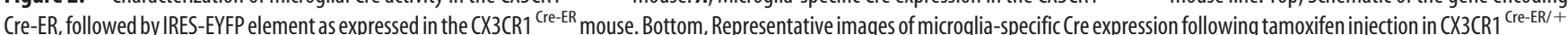
mice. Scale bar, $20 \mu \mathrm{m} . B$, Generation of the $\mathrm{CX} 3 \mathrm{CR}{ }^{\mathrm{Cre}-\mathrm{ER} /{ }^{+}} ; \mathrm{Ai} 9$ mouse line by crossing the $\mathrm{CX} 3 \mathrm{CR} 1{ }^{\mathrm{Cre}-\mathrm{ER} /+}$ mouse with the Rosa $26^{\text {tDTomato }}$ reporter line (Ai9). Seventy-five milligrams per kilogram tamoxifen was administered intraperitoneally to P15 animals over $5 \mathrm{~d}$, and tissue was analyzed $\sim 30 \mathrm{~d}$ following the final tamoxifen injection. $\boldsymbol{C}$, Representative images depicting GFP coimmunofluorescence with tdTomato in the hippocampus and spleen in $\mathrm{CX} 3 \mathrm{CR} 1^{\text {Cre-ER/+}} ;$; Ai9 mouse. Scale bar, $50 \mu \mathrm{m}$. D, Quantification of GFP:tdTomato cofluorescence throughout the CNS and the spleen, which shows high GFP + :tdTomato + reporting throughout the CNS with low coexpression in the spleen.

a young-adult age (P60; Fig. 1E). Also microglial VPS35 expression increased in response to an LPS stimulus (Fig. 1E), implicating VPS35 in the LPS-stimulated microglial response.

Increased microglial density and activity and altered microglial morphology in the adult hippocampus of microglial VPS35-depleted mice

To determine whether microglial VPS35 plays a role in vivo, we generated VPS3 $5^{\text {flox/llox }}$ :CX3CR $1{ }^{\text {Cre-ER/+ }}$ mice by crossing mice possessing the floxed VPS35 allele (VPS3 $5^{\text {flox/flox }}$ ) with CX3CR1 ${ }^{\text {Cre-ER/+ }}$ mice. The CX3CR1 ${ }^{\text {Cre-ER }}$ mouse line was chosen for the following reasons: (1) it expresses Cre-ER under the control of the CX3CR1 promoter expressed in macrophages/monocytes/microglial cells
(Parkhurst et al., 2013); and (2) the CX3CR1 promoter in the CX3CR $1^{\text {Cre-ER }}$ mouse line is tagged with enhanced yellow fluorescent protein (EYFP; (Fig. 2A), which can be used to identify all CX3CR1-expressing cells, including microglia and macrophages (Parkhurst et al., 2013). To confirm microglial-specific Cre-ER expression, we crossed CX3CR $1{ }^{\text {Cre-ER }}$ with the Rosa $26^{\text {tDTomato }}$ reporter line (Fig. 2B). Tamoxifen was administered over $5 \mathrm{~d}$ to CX3CR $1{ }^{\text {Cre-ER }}$ :Rosa2 $6^{\text {tDTomato }}$ mice, starting at P15. This age was chosen for tamoxifen administration since murine microglia do not attain a mature phenotype until $\sim$ P14 (Hirasawa et al., 2005; Bennett et al., 2016) and because VPS35 is highly expressed in microglia at this age (Fig. $1 E$ ). Thirty days following the final tamoxifen injection, the CX3CR1-driven Cre remained active in 

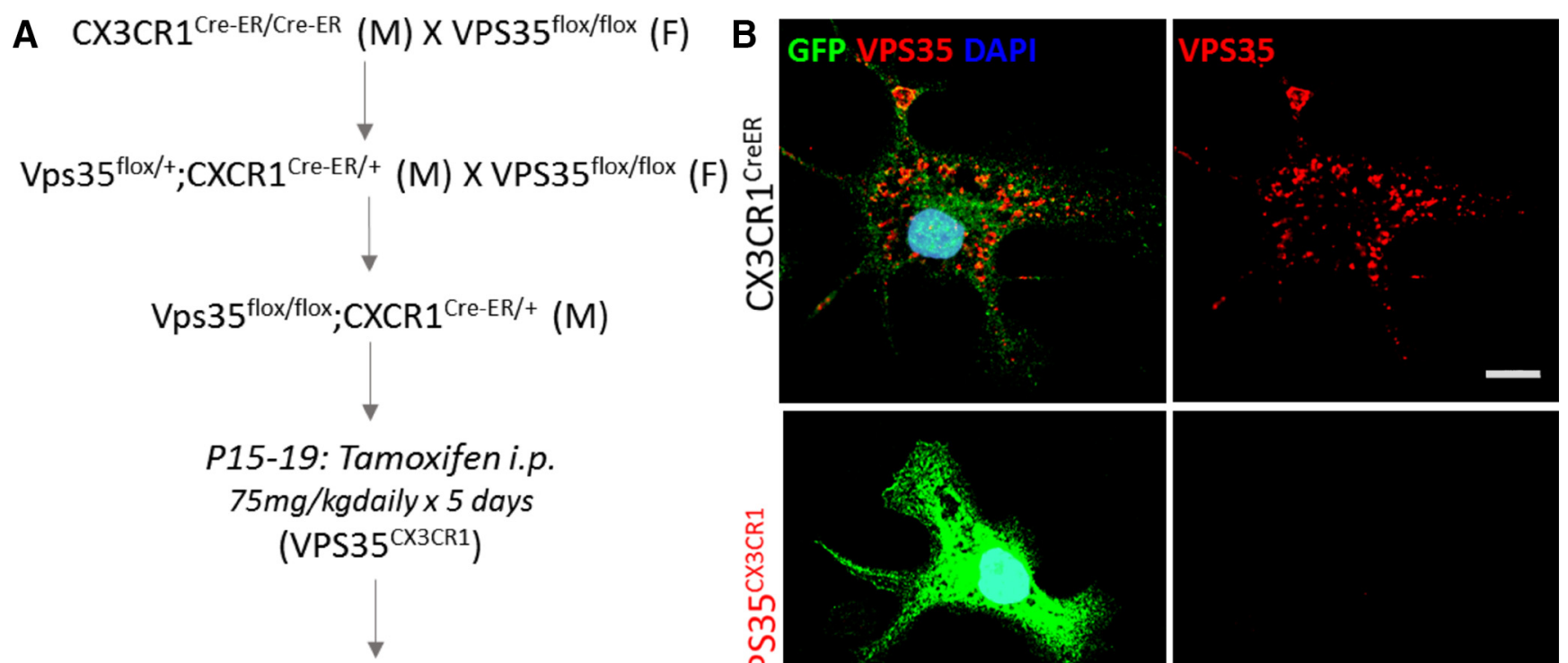

P 50: Phenotypic analyses
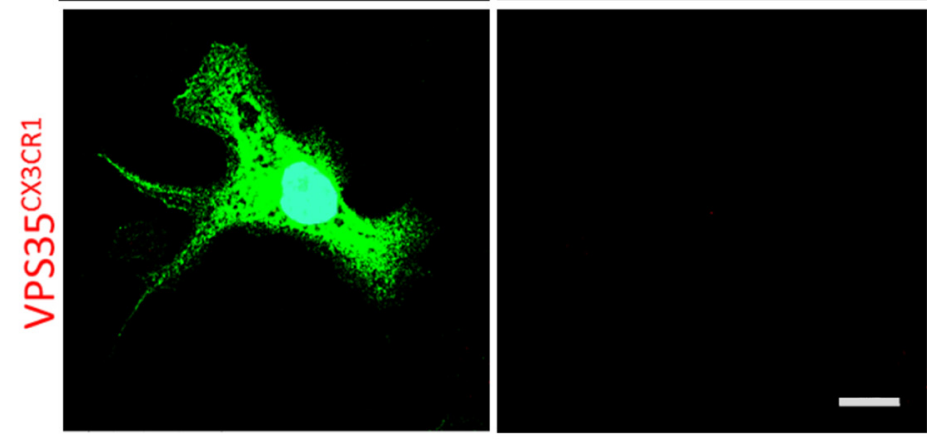

C

D

\section{Body Weight}
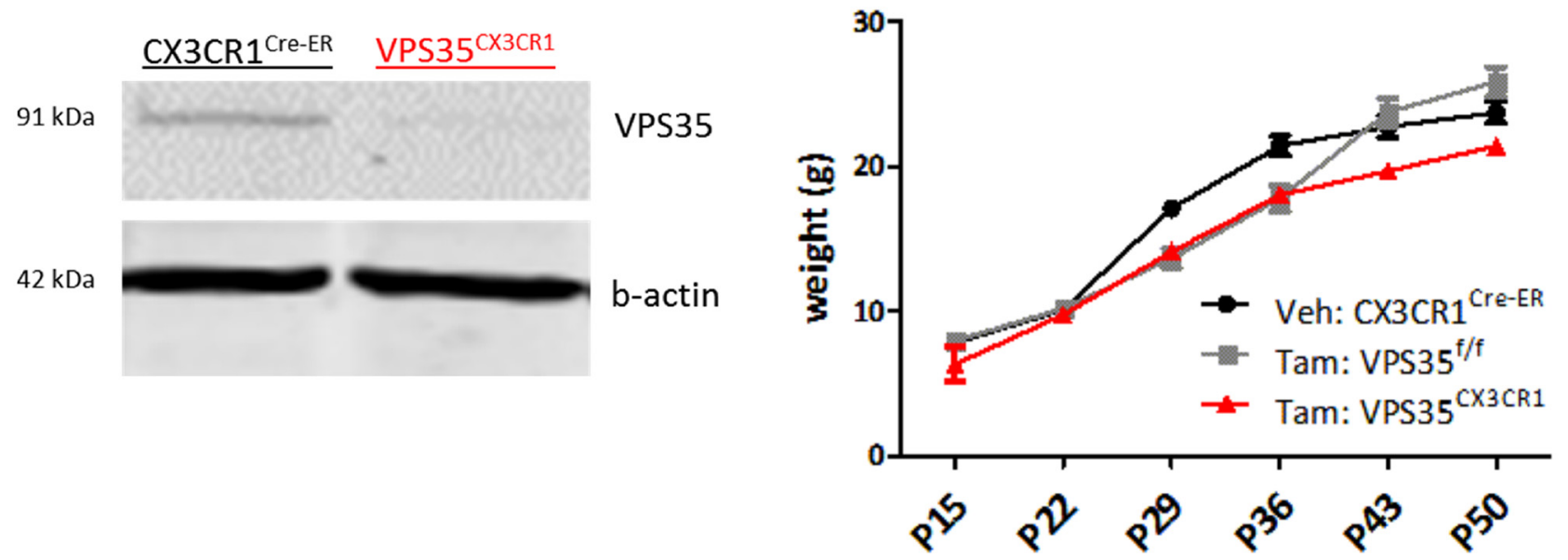

Figure 3. Generation of the VPS35 ${ }^{\text {CX3CR1 }}$ mouse. $A$, Diagram outlining the treatment strategy implemented to generate VPS35 ${ }^{\text {CX3CR1 }}$ mice. VPS35 flox/flox female mice were crossed with male CX3CR1 ${ }^{\text {Cre-ER/Cre-ER }}$ mice followed by subsequent backcrossing with female VPS3 $5^{\text {flox/flox }}$ mice to generate male VPS35 ${ }^{\text {floxfllox}}$; CX3CR1 ${ }^{\text {Cre-ER/+ }}$ (VPS35 ${ }^{\text {CX3CR1-Cre-ER) }}$ mice, subsequently treated with tamoxifen or corn oil (controls) at P15-P19 to generate VPS35 ${ }^{\text {CX3CR1/+ }}$ mice (labeled throughout text as VPS35 ${ }^{\text {CXCR1 }}$ ). Unless otherwise noted in the text, control data reported are from male

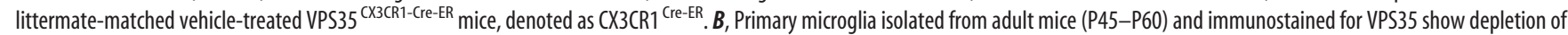
VPS35 from VPS35 ${ }^{\text {CX3CR1 }}$ microglia. Scale bar, $10 \mu \mathrm{m}$. C, Microglia isolated from the brains of adult VPS35 ${ }^{\text {CX3CR1 }}$ mice and vehicle-treated controls were immediately lysed and analyzed for protein levels of VPS35 via Western blot to exhibit microglia-specific depletion of VPS35 in the CNS of VPS35 ${ }^{\text {CX3CR1 }}$ mice. D, Weight loss of VPS35 ${ }^{\text {CX3CR1 }}$ mice compared with vehicle-treated (CX3CR1 ${ }^{\text {Cre-ER) }}$ and tamoxifen-treated (Tam VPS35 $5^{\text {flox/flox }}$ ) controls.

microglia, as evidenced by tdTomato ${ }^{+}$immunofluorescence in the brain, but little in peripheral macrophages/monocytes in the spleen (Fig. 2C,D), due to the high turnover rate of peripheral macrophages/monocytes versus the slow turnover rate of microglia, which was in accord with the literature (Parkhurst et al., 2013).

Using the same protocol of tamoxifen treatment (intraperitoneal injection at P15, examined at P50) of VPS35 flox/flox: CX3CR1 ${ }^{\text {Cre-ER/+ }}$ mice (referred to in this text as VPS35 ${ }^{\text {CX3CR1 }}$ mice; Fig. $3 A$ ), VPS35 was depleted in primary microglia from adult VPS3 $35^{\text {CX3CR1 }}$ mice treated with tamoxifen, but not corn oil, as confirmed by immunofluorescent staining (Fig. 3B) and West- ern blot analyses (Fig. 3C). We thus chose the above protocol of tamoxifen treatment (Fig. 3A) to study VPS35's function in adult murine microglia in vivo. Notice that the body weight was slightly lower in VPS35 ${ }^{\text {CX3CR1 }}$ mice than that of control mice treated with tamoxifen (Fig. 3D), implicating an in vivo function for microglial VPS35.

We then examined the cell density and morphological features of $\mathrm{GFP}^{+}$cells in the brains of VPS3 ${ }^{\mathrm{CX} 3 \mathrm{CR} 1}$ mice treated with tamoxifen. As a control, CX3CR $1^{\mathrm{Cre}-\mathrm{ER} /+}$ mice (without the floxed VPS35 allele) treated with tamoxifen were used to ensure any tamoxifen-specific effects on microglial activity were accounted for during our initial assessments. Total $\mathrm{GFP}^{+}$cell density by re- 

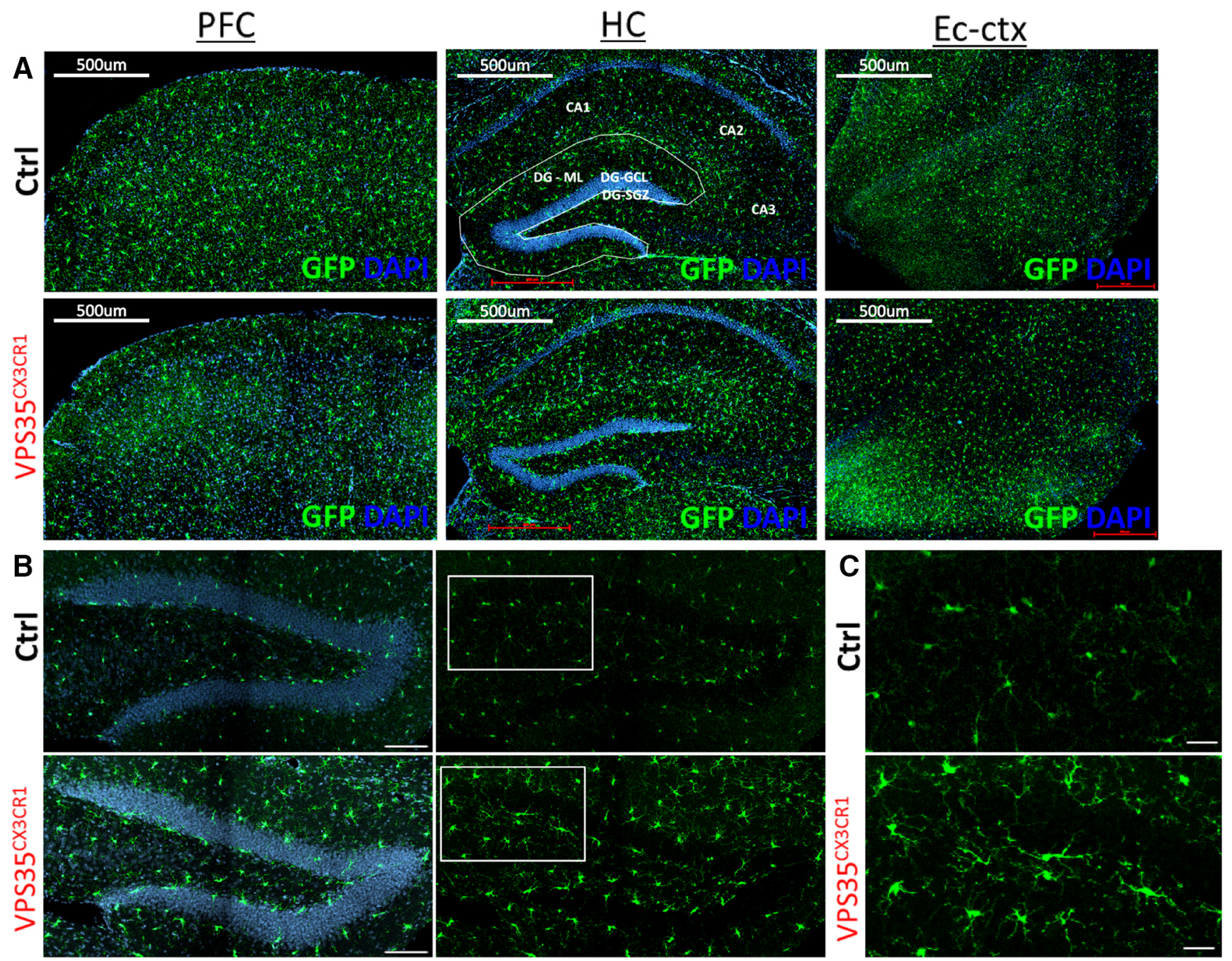

D Microglial Density

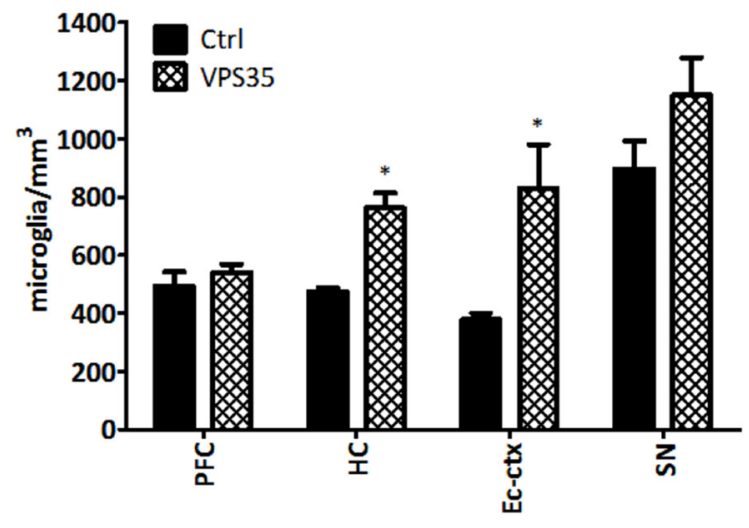

E Hippocampal Microglial Density

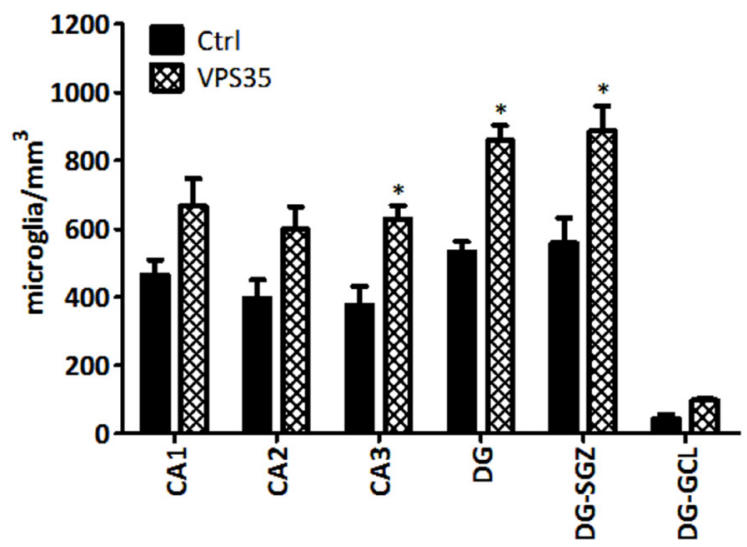

Figure 4. Regional-specific increase in microglial density following VPS35 depletion. $\boldsymbol{A}-\boldsymbol{E}$, Microglial VPS35 loss of function affects a regional-specific increase in microglial density. $\boldsymbol{A}$, Representative images from the prefrontal cortex (PFC), hippocampus (HC), molecular layer (ML), granular cell layer ( GCL), subgranular zone (SGZ), and Ec-Ctx. $\boldsymbol{B}$, Representative images of GFP immunofluorescence in the DG. White boxes represent the region shown in C. Scale bar, $100 \mu \mathrm{m}$. C, Enlarged images of GFP + cells in the SGZ suggest altered morphology of VPS35 ${ }^{C \times 3 C R 1}$ microglia. Scale bar, $50 \mu \mathrm{m}$. D, Statistical analysis of microglial density by region. Ctrl, CX3CR1 ${ }^{\text {Cre-ER/+ }}$; VPS35, VPS35 ${ }^{\mathrm{CX} 3 \mathrm{CR} 1}$ (Student's unpaired $t$ test, $n=4, \mathrm{PFC}: p=0.20 ; \mathrm{HC}: p<0.0001$; Ec-Ctx: $p=$ $0.0023 ; \mathrm{SN}: p=0.035)$. E, Statistical analysis of hippocampal microglial density by hippocampal region. Ctrl, CX3CR1 ${ }^{\mathrm{Cre}-\mathrm{ER} /+}{ }^{+}$; VPS35, VPS35 ${ }^{\mathrm{CX} 3 \mathrm{CR} 1}$. GCL, Granular cell layer. (Student's unpaired $t$ test, $n=4 ; \mathrm{CA1}: p=0.071 ; \mathrm{CA2}: p=0.058, \mathrm{CA3}: p=0.009 ; \mathrm{DG}: p=0.001 ; \mathrm{SGZ}: p=0.02 ; \mathrm{GCL}: p=0.06)$. For all analyses, statistical significance $\left(^{*} p \leq 0.05\right)$.

gional volume was calculated, revealing a regional-specific increase of cell density in VPS35 ${ }^{\text {CX3CR1 }}$ mice, compared with that of controls (Fig. 4A,D). Most notably, the hippocampus and Ec-Ctx, vulnerable regions in the $\mathrm{AD}$ brain, showed significant increases in $\mathrm{GFP}^{+}$cell density (Fig. $4 B-D$ ), with a notable increase in the subgranular zone (SGZ) of the DG (Fig. 4C,E). These GFP ${ }^{+}$cells are primarily microglia, because $>90 \%$ of $\mathrm{GFP}^{+}$cells expressed TMEM119 (transmembrane protein 119; Fig. 5A,B), a 

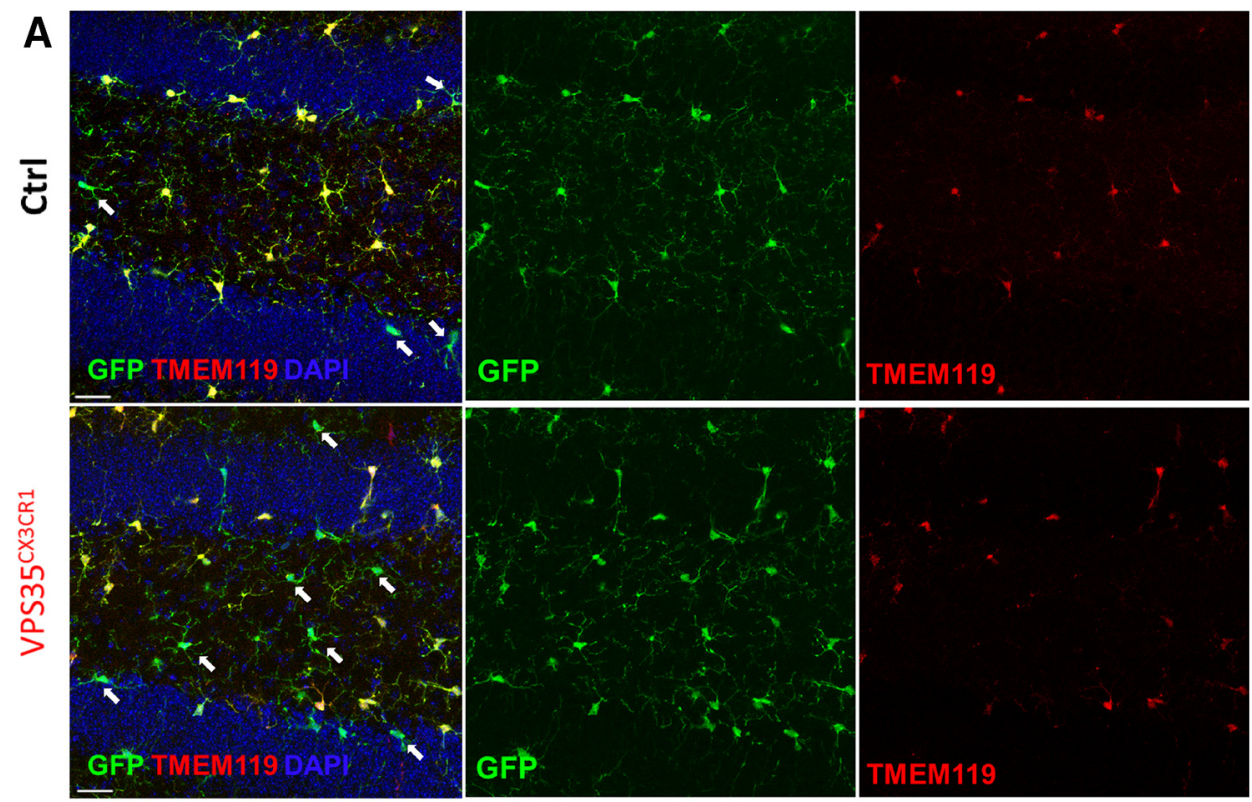

\section{B}
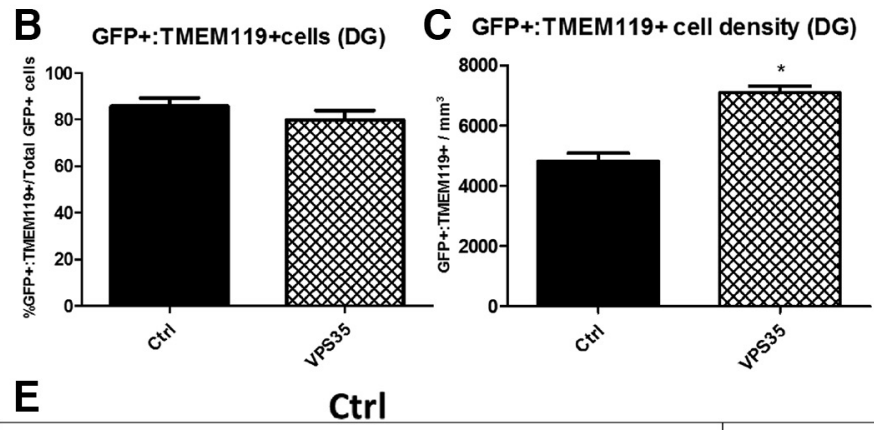

D GFP+:TMEM119-cell density (DG)
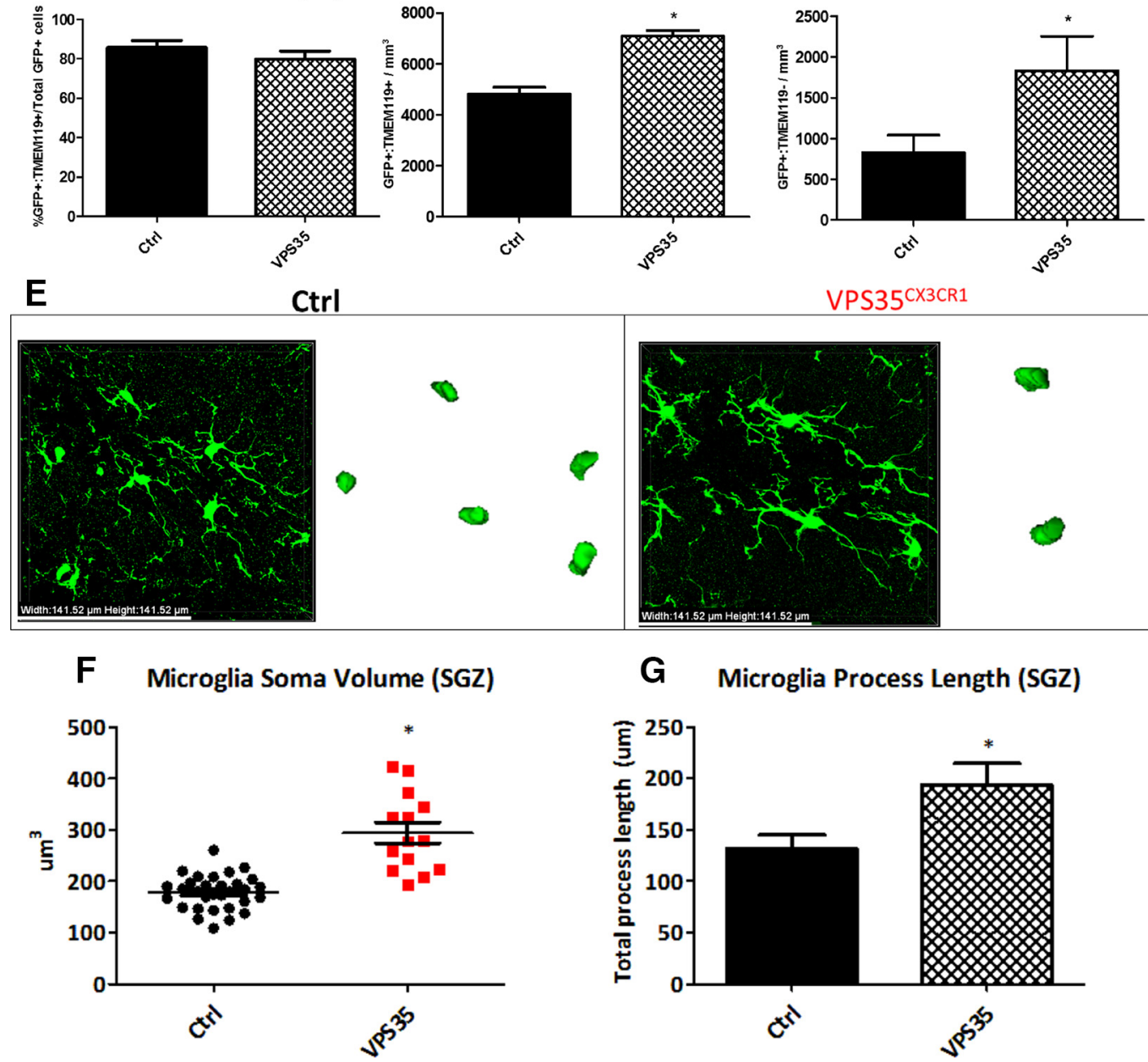

Figure 5. Infiltration of peripheral macrophages and altered SGZ microglial morphology following VPS35 depletion. $\boldsymbol{A}$, Representative images of GFP:TMEM119 coimmunofluorescence in the DG. Scale bar, $50 \mu \mathrm{m}$. $\boldsymbol{B}$, Statistical analysis of GFP ${ }^{+}$and TMEM $119^{+}$cells indicates $>90 \%$ of GFP + cells express TMEM119. C, Statistical analysis of increased GFP ${ }^{+}$:TMEM119 ${ }^{+}$cell density in the DGs of VPS35 ${ }^{\text {CX3CR1 }}$ mice (Student's unpaired $t$ test, $\left.n=5, p=0.0002\right)$. D, Statistical analysis of increased GFP ${ }^{+}$:TMEM119 ${ }^{-}$cell density in the DGs of VPS35 ${ }^{\text {CX3CR1 }}$ mice implicates an infiltration of peripheral macrophages (Student's unpaired t test, $n=5, p=0.03$ ). E, Representative images of SGZ microglial morphology and $3 \mathrm{D}$ visualizations of soma volume as calculated using Reconstruct software. Scale bar, $141.52 \mu \mathrm{m}$. F, Statistical analysis of increased microglia soma volume in SGZ microglia of VPS35 ${ }^{\text {CX3CR1 }}$ mice. Ctrl, CX3CR1 ${ }^{\text {Cre-ER/+ }}$; VPS35, VPS35 ${ }^{\text {CX3CR1 }}$ (Student's unpaired $t$ test, $n=14-31$, sampled from 3 animals per group, with $\geq 4$ microglia per animal analyzed, $p<0.0001)$. G, Statistical analysis of increased total microglia process length in SGZs of VPS35 ${ }^{\text {CX3CR1 }}$ mice.

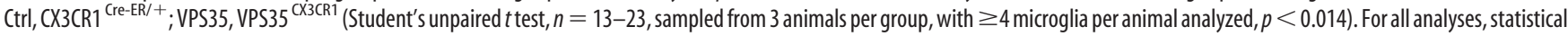
significance $\left({ }^{*} p \leq 0.05\right)$. 
marker for microglia that is undetectable in macrophages (Bennett et al., 2016; Satoh et al., 2016). Interestingly, the cell densities of both GFP:TMEM119 (Fig. 5C) and GFP;TMEM119 microglial cells were higher in the VPS35CX3CR1 hippocampi than in those of controls (Fig. $5 A, D$ ), implicating an increase of peripheral macrophage infiltration. $\mathrm{GFP}^{+}$cellular morphology appeared to be altered in the VPS35 ${ }^{\text {CX3CR1 }}$ SGZ (Fig. $4 C$ ), so morphological features of SGZ GFP ${ }^{+}$cells were analyzed by measuring soma volume and total length of cell processes. VPS $35^{\text {CX3CR1 }}$ SGZ microglia displayed increased soma volume (Fig. $5 E, F$ ), as well as increased length of cell processes (Fig. $5 E, G$ ).

Increased microglial density and altered microglial morphology are often associated with increased microglial activation. We thus assessed microglial activity using markers known to be upregulated in concurrence with microglial activation (e.g., IBA1, CD16/32). There were significant increases in hippocampal IBA1 and CD16/32 [CD16: low-affinity IgG Fc receptor III (FcR III); CD32: FcR II; a marker upregulated under M1 proinflammatory conditions] immunofluorescence in VPS35 ${ }^{\text {CX3CR1 }}$ mice (Fig. $6 A-D$ ), both of which were also significantly upregulated in the SGZ of the VPS35 ${ }^{\mathrm{CX} 3 \mathrm{CR} 1}$ DG (Fig. $6 B, D)$. Hippocampal microglial activity was also assessed by probing hippocampal tissue lysates for IBA1 and CD11b (cluster of differentiation molecule 11b/CR3A/ITGAM, a molecule shown to upregulate in concurrence with microglial proinflammatory conditions). Western blot analysis showed increased relative density of both IBA1 and CD11b in VPS35 ${ }^{\mathrm{CX} 3 \mathrm{CR} 1}$ hippocampal tissue (Fig. $6 E-G$ ). These results thus support the idea that microglial activation is upregulated in the VPS35 ${ }^{\text {CX3CR1 }}$ brain in a regional-specific manner (e.g., hippocampus and SGZ).

\section{Elevated microglial differentiation following microglial VPS35 loss of function}

To further analyze potential regulation of microglial density in VPS35 ${ }^{\text {CX } 3 \text { CR1 }}$ mice, we wondered whether loss of microglial VPS35 results in elevated microglial proliferation, thus increasing microglial density. To test this view, VPS35 ${ }^{\text {CX3CR1 }}$ mice and CX3CR 1 Cre-ER littermate controls were administered BrdU (intraperitoneally, 4 times over $12 \mathrm{~h}$ ) and killed $24 \mathrm{~h}$ after the commencement of BrdU treatment (Fig. 7A). Hippocampal $\mathrm{BrdU}^{+}: \mathrm{GFP}^{+}$cells were quantified, however, with no observable difference in the density of $\mathrm{BrdU}^{+}: \mathrm{GFP}^{+}$ cells in the DGs of VPS35 ${ }^{\text {CX3CR1 }}$ mice compared with controls (Fig. $7 B, C$ ), excluding microglial proliferation as the possible underlying mechanism.

We then examined microglial differentiation/migration in control and VPS35 ${ }^{\mathrm{CX} 3 \mathrm{CR} 1}$ mice. To this end, mice were administered $\mathrm{BrdU}$ and killed $7 \mathrm{~d}$ later (Fig. $7 D$ ). $\mathrm{BrdU}^{+}: \mathrm{GFP}^{+}$cells indicated new microglial cells that had either differentiated or migrated from surrounding regions since the initial BrdU injection. The hippocampi of CX3CR $1_{\text {Cre-ER }}$ controls often contained no or few BrdU:GFP cells. By contrast, BrdU:GFP cells were frequently observed in the DGs of VPS $35_{\mathrm{CX} 3 \mathrm{CR} 1}$ mice (Fig. $7 E-G$ ), suggesting that increased microglial density might be a result of increased microglial differentiation and/or migration. To determine whether other glial cell types (astrocytes and oligodendrocytes) were affected in a similar manner, we examined additional glial markers for BrdU coimmunofluorescence, observing no significant differences (Fig. $7 \mathrm{H}-\mathrm{J})$.
Increased neural stem cell proliferation, but reduced neuronal differentiation, in microglial VPS35-depleted DGs Following the initial BrdU analyses, we found it interesting that VPS35 ${ }^{\text {CX3CR1 }}$ mice showed significantly higher numbers of $\mathrm{BrdU}^{+}$ cells in the SGZ, a primary site of adult hippocampal neurogenesis, at both 1 and $7 \mathrm{~d}$ following BrdU injections (Fig. $8 A-F$ ), implicating both elevated neural stem/progenitor cell (NSC/NPC) proliferation and survival. We thus further assessed for additional indices of hippocampal neurogenesis in VPS35 ${ }^{\mathrm{CX} 3 \mathrm{CR} 1}$ mice. Ki67 is a proliferative marker that can be used to identify dividing cells throughout the cell cycle with the exception of G0 and early G1 phases (Zhang and Jiao, 2015). Ki67:BrdU coimmunofluorescence and Ki67 quantification indicated increased $\mathrm{Ki}^{+} 7^{+}$cell density in the VPS35 ${ }^{\text {CX3CR1 }}$ SGZ, compared with that of controls (Fig. 8G,H), supporting the notion of increased NSC/NPC proliferation. The ratio of $\mathrm{Ki}_{67}{ }^{+}: \mathrm{BrdU}^{+}$cells to total $\mathrm{BrdU}^{+}$cells also increased in the VPS35 ${ }^{\mathrm{CX} 3 \mathrm{CR} 1} \mathrm{SGZ}$ (Fig. $8 I$ ), suggesting impaired cell-cycle exit in these NSC/NPCs. These results suggest that microglial VPS35 loss of function disturbs hippocampal neurogenesis by increasing NSC/NPC proliferation as well as disrupting cell-cycle exit.

To determine whether microglial VPS35 loss of function affects hippocampal neuronal differentiation, mice underwent BrdU treatment (Fig. 7D) and hippocampi were immunostained for DCX, a marker specifically expressed by cells of a neuronally determined lineage (late neuroblasts and immature neurons; Fig. $9 A, B)$. Despite an increased number of $\mathrm{BrdU}^{+}$cells in the SGZ of in VPS3 $5^{\mathrm{CX} 3 \mathrm{CR} 1}$ mice, the percentage of $\mathrm{BrdU}^{+}$cells expressing DCX was significantly lower in VPS $35^{\text {CX3CR1 }}$ hippocampi (Fig. $9 B$ ), suggesting reduced neuronal differentiation in the VPS35 ${ }^{\text {CX3CR1 }}$ hippocampus. Together, these unanticipated results suggest a model in which microglial VPS35 loss of function disrupts adult hippocampal neurogenesis, increasing the presence of NSC/ NPCs while differentially reducing neuronal differentiation and arresting cell-cycle exit (Fig. 9G).

\section{Reduced newborn neurons and their dendritic morphogenesis in microglial VPS35-depleted DGs}

Given that neuronal differentiation was reduced in VPS35 ${ }^{\text {CX3CR1 }}$ hippocampi, we examined whether there existed an overall reduction in newborn neurons following microglial VPS35 depletion by quantifying total DCX immunofluorescence (Fig. 9C-F). In support of this speculation, DCX quantification revealed a significant reduction of newborn neurons in the VPS35 ${ }^{\text {CX3CR1 }}$ hippocampus (Fig. 9C,D). Reduced DCX levels in the hippocampi of VPS35 ${ }^{\text {CX3CR1 }}$ mice were confirmed by Western blot analysis (Fig. 9E,F). Interestingly, the overall complexity of $\mathrm{DCX}^{+}$neuronal processes in VPS35 ${ }^{\mathrm{CX} 3 \mathrm{CR} 1}$ hippocampi appeared to be diminished (Fig. 9C).

To further assess the effects of microglial VPS35 depletion on newborn neurons in the adult DG, a retroviral-mediated labeling strategy was implemented to visualize dividing cells and their progeny. DGs of VPS35 ${ }^{\text {CX3CR1 }}$ mice were stereotaxically injected with a GFP-labeled retrovirus (Fig. 10A). One month following retrovirus injection, mice were killed and morphological features of GFP-expressing neurons in the DGs were examined. GFP ${ }^{+}$ neurons in the DGs of VPS35 ${ }^{\mathrm{CX} 3 \mathrm{CR} 1}$ mice exhibited significant reductions in dendritic process length and complexity (Fig. 10B-E) and reduced density of dendritic spines (Figs. 10F,G). These results provide additional evidence supporting a model of disturbed adult hippocampal neurogenesis and neuronal differentiation, implicating a novel role of microglial VPS35 in the regulation of newborn neuronal maturation in the adult CNS, in 

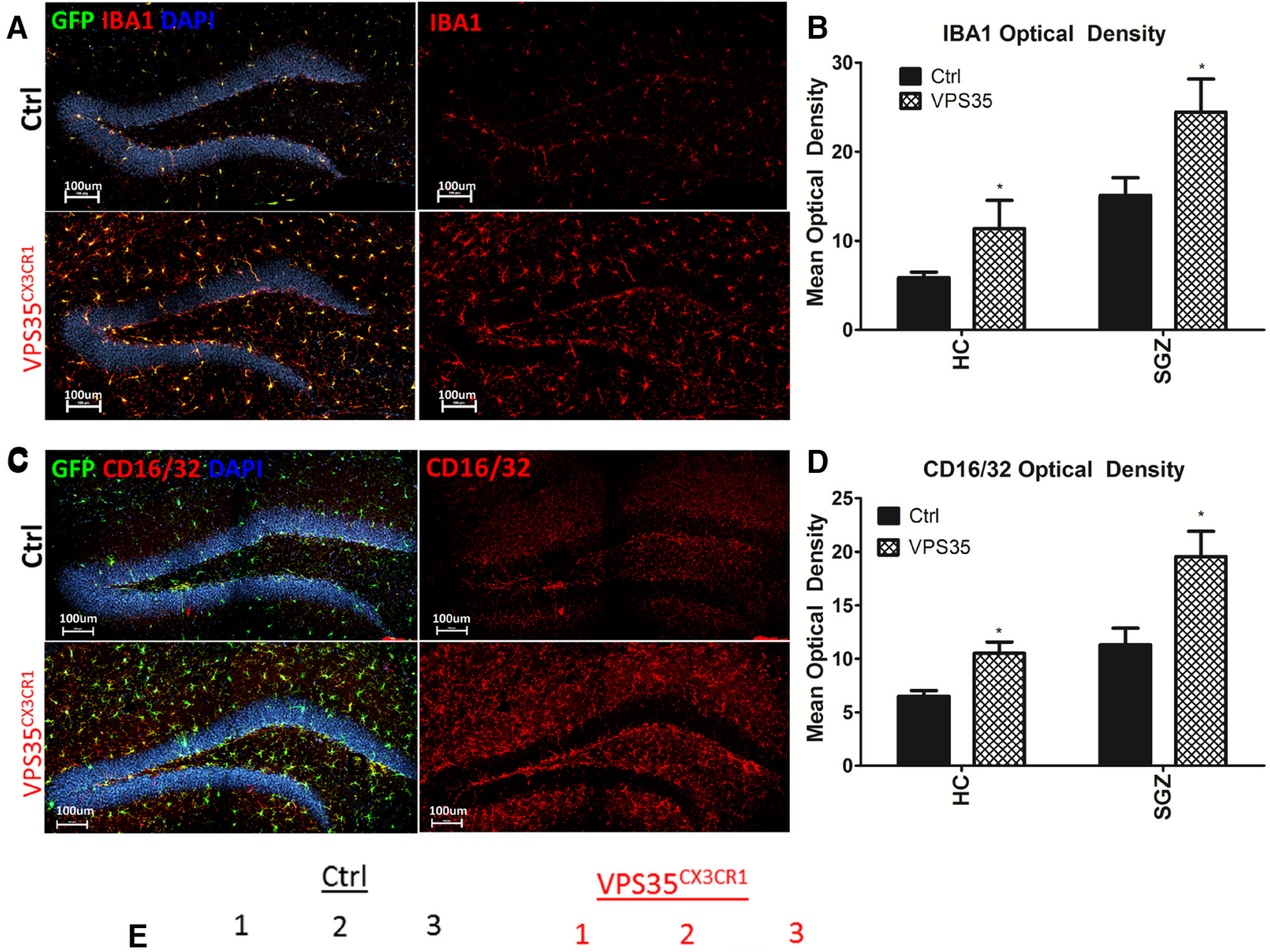

$170 \mathrm{kDa}$

$\mathrm{CD} 11 \mathrm{~b}$

$17 \mathrm{kDa}$

IBA1

$37 \mathrm{kDa}$

GAPDH

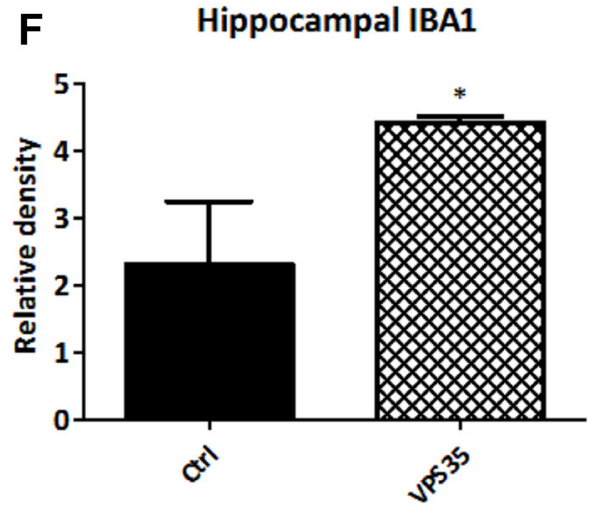

G Hippocampal CD11b

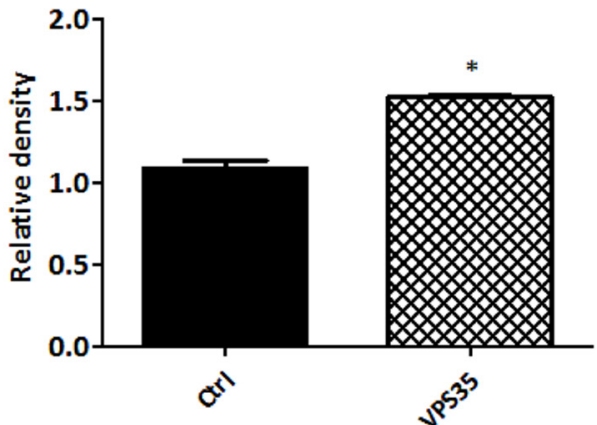

Figure 6. Upregulated hippocampal microglial activity following microglial VPS35 depletion. $A$, Representative images of IBA1 immunofluorescence in the hippocampus following microglial VPS35 loss of function. B, Statistical analysis of hippocampal IBA1 fluorescent optical density [Student's unpaired $t$ test, $n=3$, hippocampus (HC): $p=0.012 ; 5 G Z: p=0.046$ ]. C, Representative images of CD16/32 immunofluorescence in the hippocampus following microglial VPS35 loss of function. D, Statistical analysis of hippocampal CD16/32 fluorescent optical density (Student's unpaired $t$ test, $n=3, \mathrm{HC}: p=0.014 ; \mathrm{SGZ}: p=0.022)$. $\boldsymbol{E}-\mathbf{G}$, Hippocampal tissue was solubilized and subjected to Western blot analysis, confirming an increase in IBA1 and identifying increased CD11b, both indicative of upregulated microglial activity (Student's unpaired $t$ test, $n=3$, IBA1: $p=0.044 ;$ (D11b: $p=0.0009$ ). For all analyses, statistical significance $\left({ }^{*} p<0.05\right)$. 
A

\begin{tabular}{|c|c|c|}
\hline $\begin{array}{c}\text { Tamoxifen } \\
\text { daily } \times 5 \text { days }\end{array}$ & $\begin{array}{l}\text { BrdU } \\
\text { treatment }\end{array}$ & $\begin{array}{c}\text { Analysis of } \\
\text { hippocampus }\end{array}$ \\
\hline VPS35저RI-CreK $\downarrow$ & $\downarrow$ & $\checkmark$ \\
\hline P15 & P48 & P49 \\
\hline
\end{tabular}

B

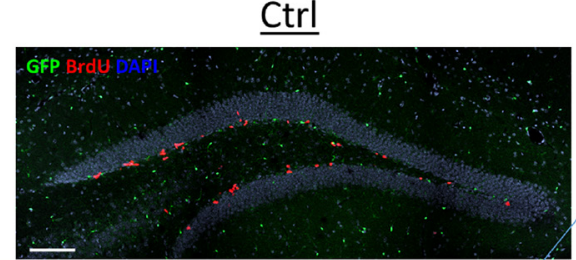

BrdU+ microglia (DG)

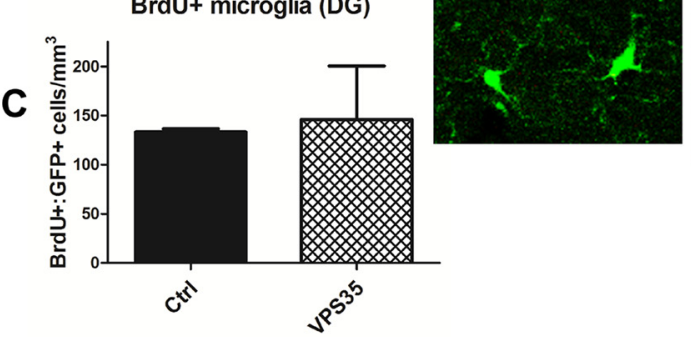

D
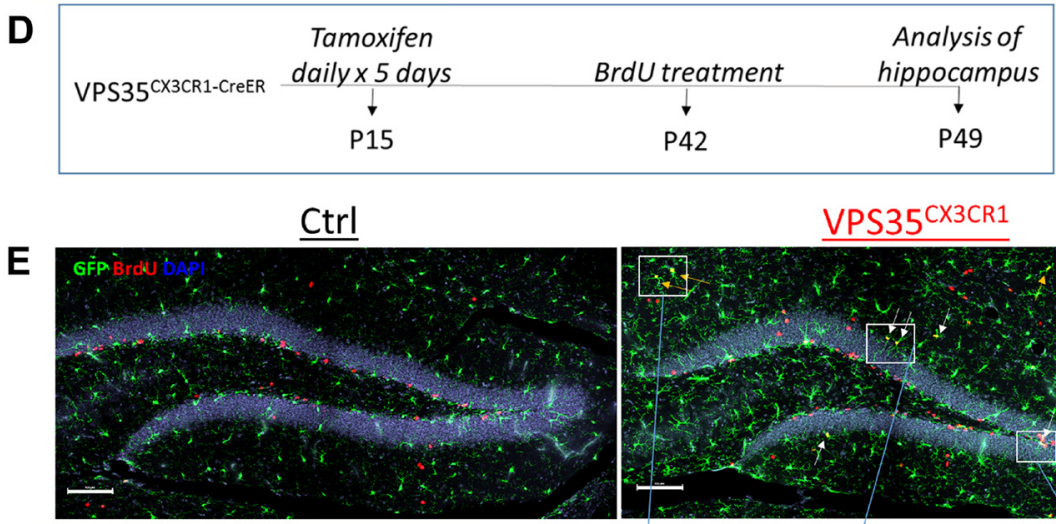

$\mathbf{F}$

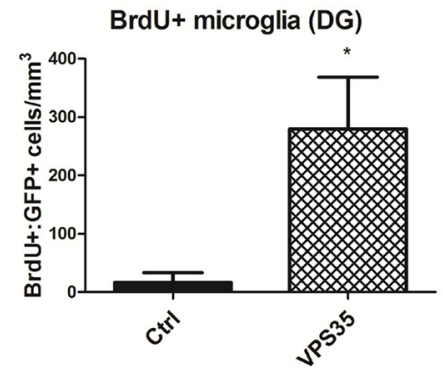

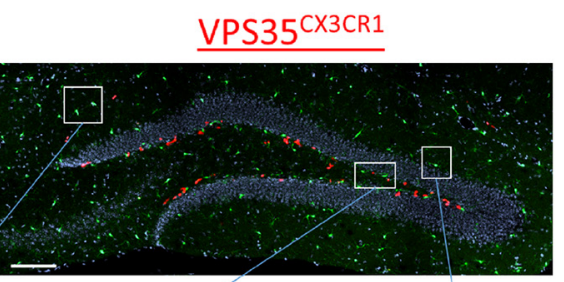

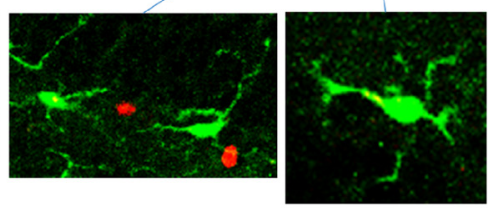

VPS35 $5^{\text {CX3CR1 }}$
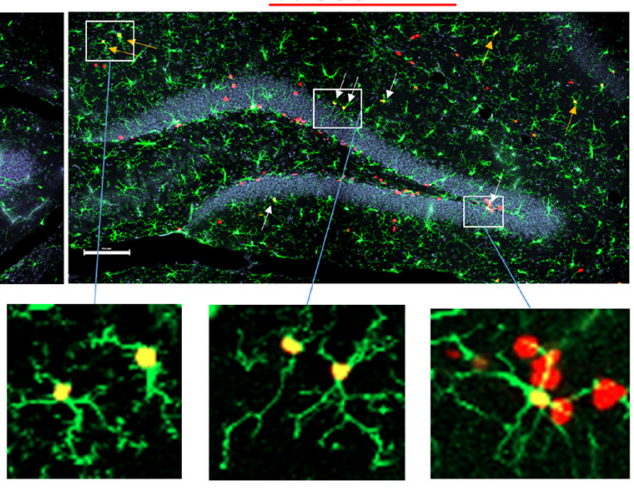

G

$\%$ GFP+

differentiated cells (DG)

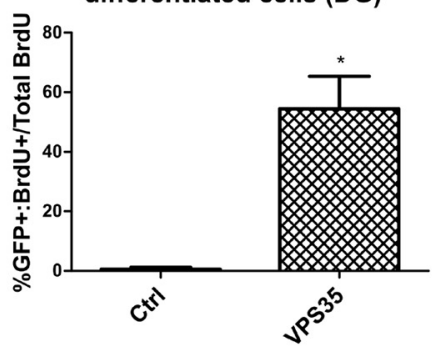

\%Olig2+

H differentiated cells (DG)

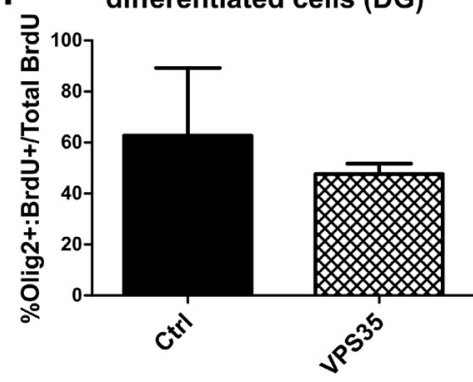

\%GFAP+

I differentiated cells (DG)

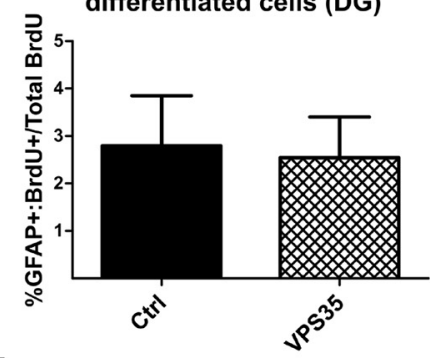

$\mathbf{J}$

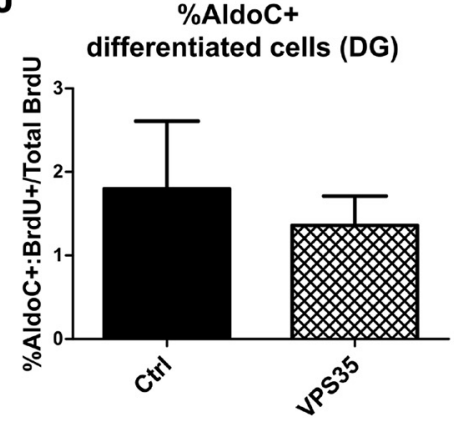

Figure 7. Increased microglial survival and/or migration in the VPS35 ${ }^{\mathrm{CX} 3 \mathrm{CR} 1}$ hippocampus. $A-C$, Analysis of hippocampal microglial proliferation. $A$, Schematic of BrdU treatment for analysis of proliferation. $\boldsymbol{C}$, Representative images of GFP:BrdU costaining. $\boldsymbol{B}$, Statistical analysis of BrdU + proliferative microglia shows no difference in microglial proliferation following microglial VPS35 loss of function (Student's unpaired $t$ test, $n=3, p=0.3528$ ). $\boldsymbol{D}-\boldsymbol{F}$, Analysis of hippocampal microglial differentiation and survival. $\boldsymbol{D}$, Schematic of BrdU treatment for analysis of NPC differentiation. $E$, Representative images of GFP:BrdU costaining show increased GFP + :BrdU + costaining in the hippocampus of VPS35 ${ }^{\text {CX3CR1 }}$ mice. $F$, Increased density of BrdU +-differentiated microglia in the DGs of VPS35 ${ }^{\times 33 C R 1}$ mice suggests increased hippocampal microglial survival or differentiation. (Student's unpaired $t$ test, $\left.n=3, p=0.0036\right)$. G-J, Statistical analysis of glial differentiation based upon percentage of BrdU + microglia $(\boldsymbol{G} ; p=0.0193)$, oligodendrocytes $(\boldsymbol{H} ; p=0.3158)$, or astrocytes $(\boldsymbol{I} ; p=0.4325 ; \boldsymbol{J} ; p=0.3337)$ out of total BrdU + cells $7 \mathrm{~d}$ following BrdU treatment (Student's unpaired $t$ test, $n=2-3$ ). For all analyses, statistical significance $\left({ }^{*} p \leq 0.05\right)$.

which microglial VPS35 deficiency causes neurodegenerative morphological deficits upon hippocampal newborn neurons before synaptic integration.

Increased microglial engulfment of postsynaptic elements following microglial VPS35 loss of function

To understand how microglial VPS35 loss of function results in impaired newborn neuronal dendritic morphogenesis and spine formation, we performed microglial-neuronal cocultures. Adult primary microglia were first isolated from control and VPS35 $5^{\text {CX3CR1 }}$ cortices of P50 mice. Notice that VPS35 ${ }^{\mathrm{CX} 3 \mathrm{CR} 1}$ microglia were GFP positive and displayed abnormally high numbers of grossly enlarged LAMP1 ${ }^{+}$vacuolar-like structures, compared with microglia of controls (Fig. 11A,B). Adult primary microglia were then cocultured with primary neurons transfected with $\mathrm{mCh}$ plasmid (Fig. 11C). Five days following addition of microglia to 
A

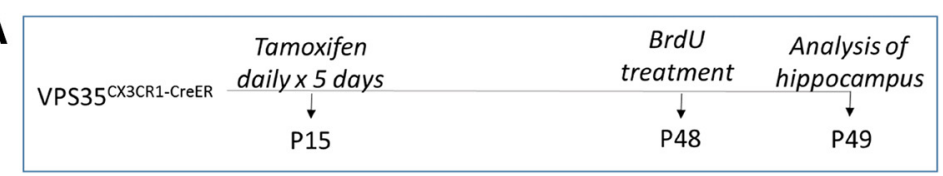

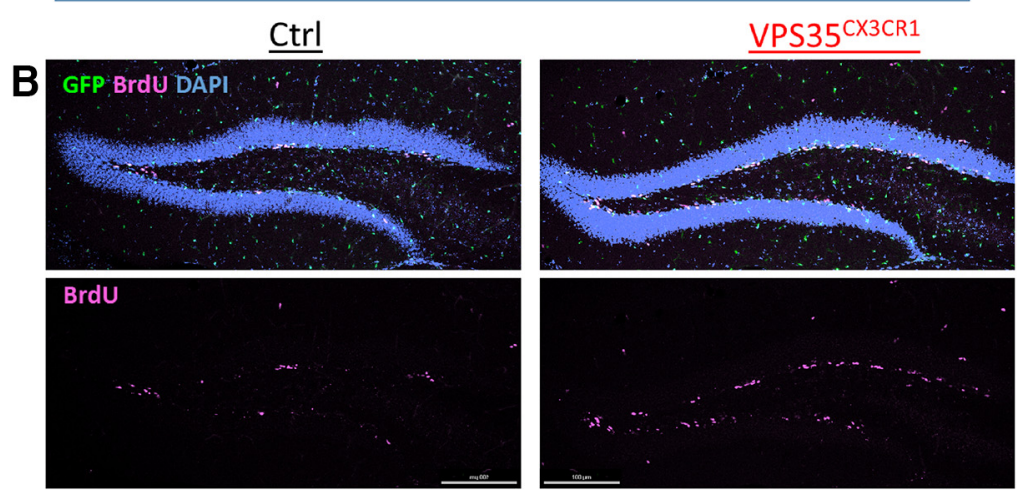

D
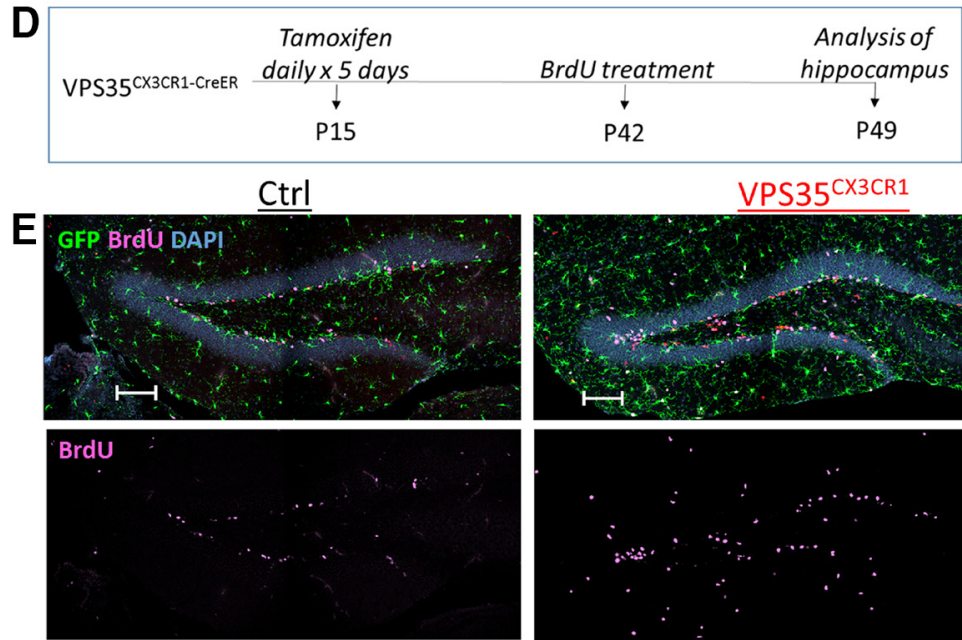

G

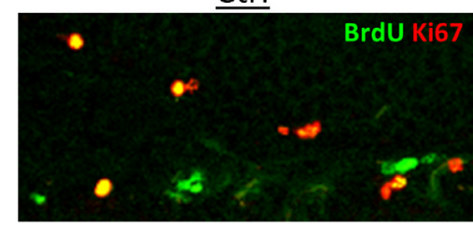

H

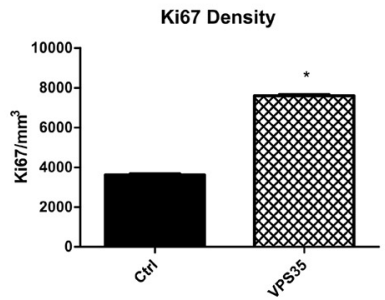

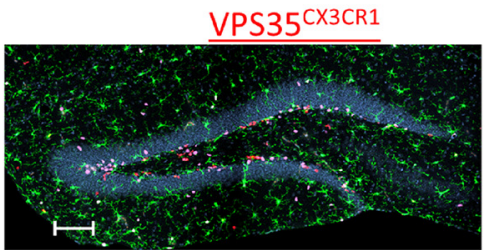

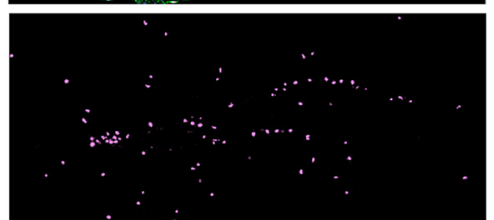

$\underline{\text { VPS35 }} 5^{\text {CX3CR1 }}$

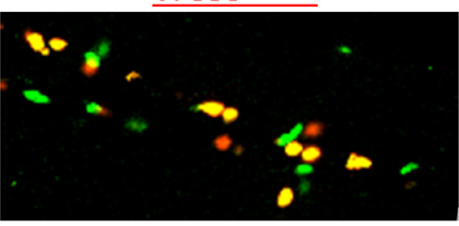

I
C BrdU Density - 24 hours

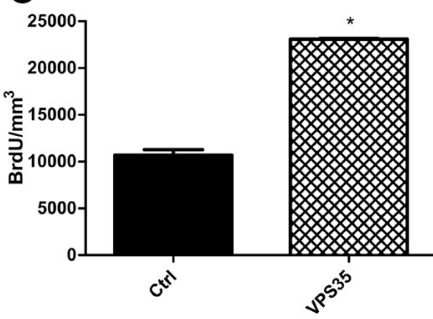

Figure 8. Aberrant hippocampal neurogenesis following microglial VPS35 loss of function, characterized by elevated neural progenitor proliferation and arrested cell-cycle exit. $A$, Animals were treated with BrdU and analyzed $24 \mathrm{~h}$ following treatment to assess BrdU + cells for proliferation. B, C. Increased BrdU density in the SGZs of VPS35 ${ }^{\text {CXCR1 }}$ mice $24 \mathrm{~h}$ following BrdU treatment (Student's unpaired $t$ test, $n=3, p=0.0001$ ) suggests increased proliferation of hippocampal NSCs following microglial VPS35 loss of function. $D$, Animals were treated with BrdU and analyzed

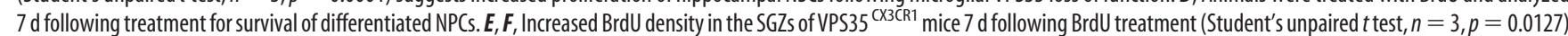
suggests an increased survival rate of hippocampal NPCs following microglial VPS35 loss of function. $\mathbf{G}, \boldsymbol{H}$, Ki67 immunofluorescence displays a significant increase in overall Ki67+ cells, suggesting an increase in Ki67+-proliferating NSCs following microglial VPS35 loss of function. I, Ki67+:BrdU + cells were quantified 1 week following BrdU treatment to assess cell-cycle exit. A significant increase in total percentage of BrdU + cells which are Ki67 + was noted, suggesting BrdU + cells may be increased due to a failure to exit the cell cycle (Student's unpaired $t$ test, $n=3, p<0.0324$ ). For all analyses, statistical significance $\left({ }^{*} p \leq 0.05\right)$.

the transfected neuronal culture, microglia were observed for mCh fluorescence. VPS35 ${ }^{\text {CX3CR1 }}$ microglia were found to exhibit a significant increase in $\mathrm{mCh}$ fluorescence (Fig. $11 D, E$ ). The increased $\mathrm{mCh}$ fluorescence was deduced to result from either an increase in microglial engulfment of $\mathrm{mCh}$ and/or an impairment in $\mathrm{mCh}$ degradation. To further test this view, we examined the specific neuronal presynaptic and postsynaptic markers synapsin-1 and postsynaptic density 95 (PSD95) in microglial- 
A

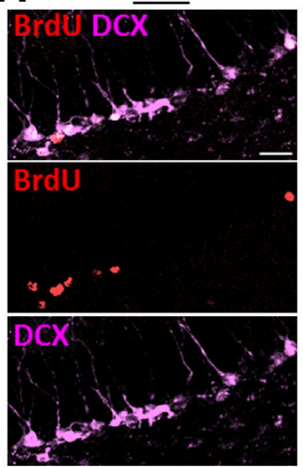

C
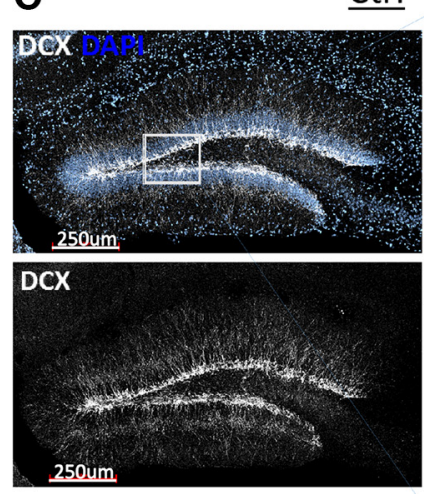

D

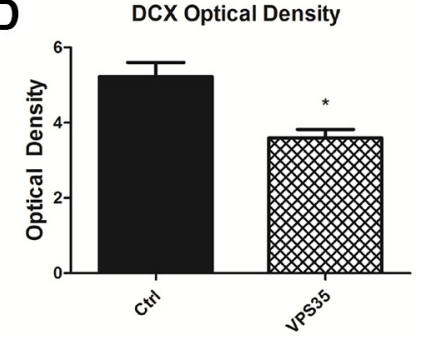

G

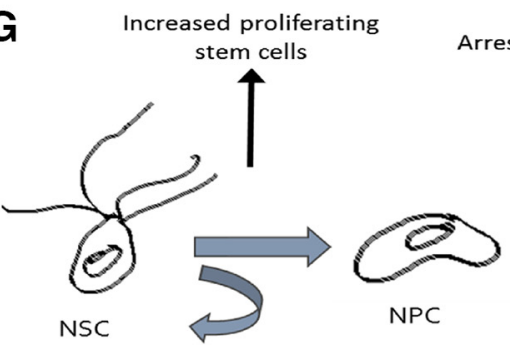

VPS35 $5^{\text {CX3CR1 }}$

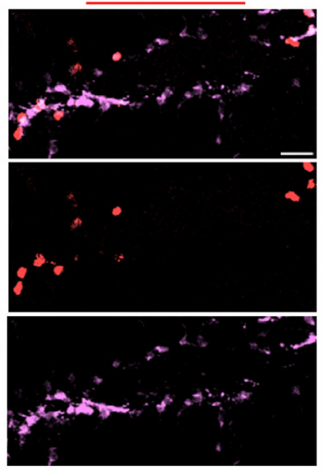

Ctrl

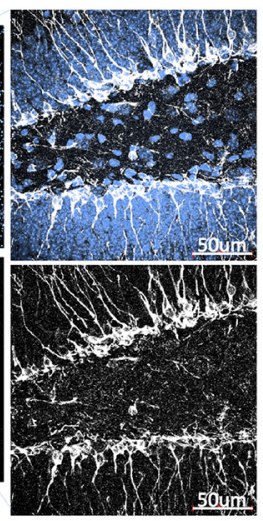

E

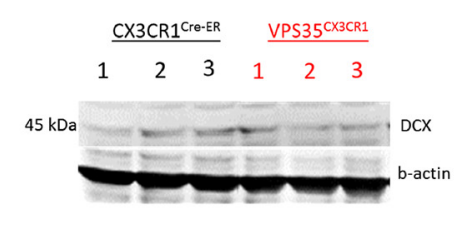

B

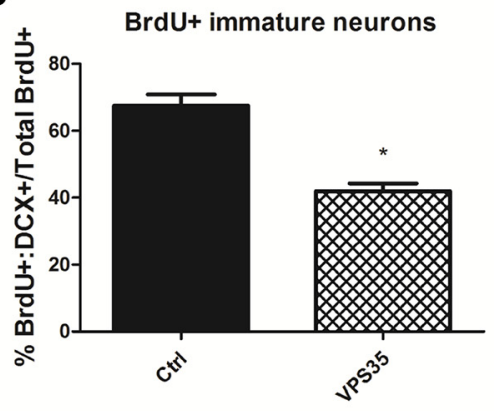

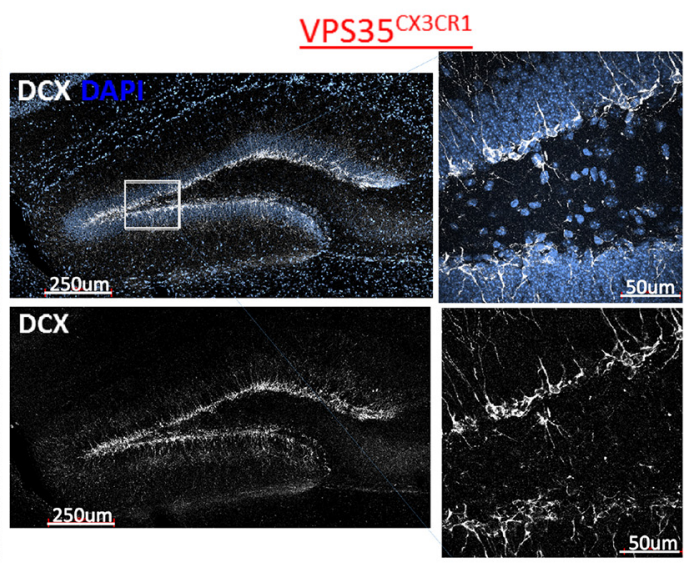

F

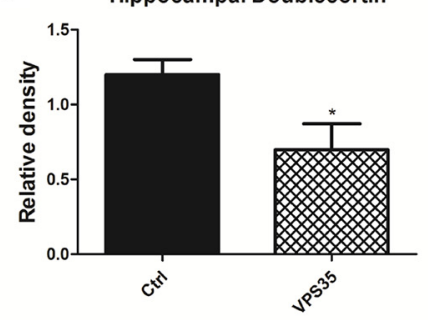

Decreased neuronal differentiation
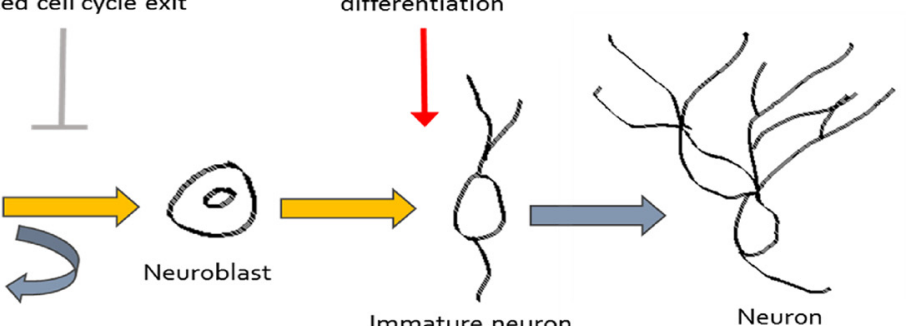

Immature neuron

DCX

MCM2

Ki67

Figure 9. A decrease of neuronal differentiation and a reduction of immature neurons in VPS35 ${ }^{\text {CX3CR1 }}$ DGs. A, Representative images of BrdU:DCX coimmunofluorescence 1 week following BrdU treatment. Scale bar, $50 \mu \mathrm{m}$. B, Statistical analysis of percentage of BrdU + cells expressing DCX 7 d following BrdU treatment (as a percentage of total BrdU + cells) indicates decreased neuronal differentiation following microglial VPS35 loss of function (Student's unpaired $t$ test, $n=3, p=0.0034$ ). C, Representative images of hippocampal DCX immunofluorescence and $60 \times$ zoomed images, demonstrating the reduced levels of DCX and DCX + processes following microglial VPS35 depletion. D, Statistical analysis of DG DCX fluorescent optical density (Student's unpaired $t$ test, $n=3, p=0.0207) . \boldsymbol{E}, \boldsymbol{F}$, Hippocampal tissue was solubilized and subjected to Western blot analysis, confirming reduced levels of DCX in VPS35 ${ }^{\text {CX3CR1 }}$ mice (Student's unpaired $t$ test, $n=3, p=$ 0.033). G, Schematic depicting the model in which microglial VPS35 loss of function affects aberrant hippocampal neurogenesis, during which an increase is observed in proliferating NSCS, concurrent with a decrease in immature neurons and arrested cell-cycle exit. For all analyses, statistical significance $\left({ }^{*} p \leq 0.05\right)$.

neuronal cocultures (Fig. 11F). A significantly higher PSD95 fluorescence, but not synapsin-1 fluorescence, was detected in VPS35 ${ }^{\text {CX3CR1 }}$ microglia (Fig. $11 G-I$ ), suggesting an increased uptake of postsynaptic, but not presynaptic, elements by
VPS35 ${ }^{\text {CX3CR1 }}$ microglia. We then tested this view in the brains of control and VPS35 ${ }^{\text {CX3CR1 }}$ mice by coimmunostaining analysis using antibodies against PSD95 and GFP. Indeed, VPS35 ${ }^{\text {CX3CR1 }}$ microglia contained more PSD95 fluorescence than those of con- 
A

\begin{tabular}{|c|c|c|c|}
\hline & $\begin{array}{c}\text { Tamoxifen } \\
\text { daily } x 5 \text { days }\end{array}$ & $\begin{array}{c}\text { Retroviral } \\
\text { Injection (DG) }\end{array}$ & $\begin{array}{l}\text { Analysis of } \\
\text { retroviral labelling }\end{array}$ \\
\hline VPS35 CX3CR1-CreER & $\downarrow$ & $\checkmark$ & $\checkmark$ \\
\hline
\end{tabular}

B
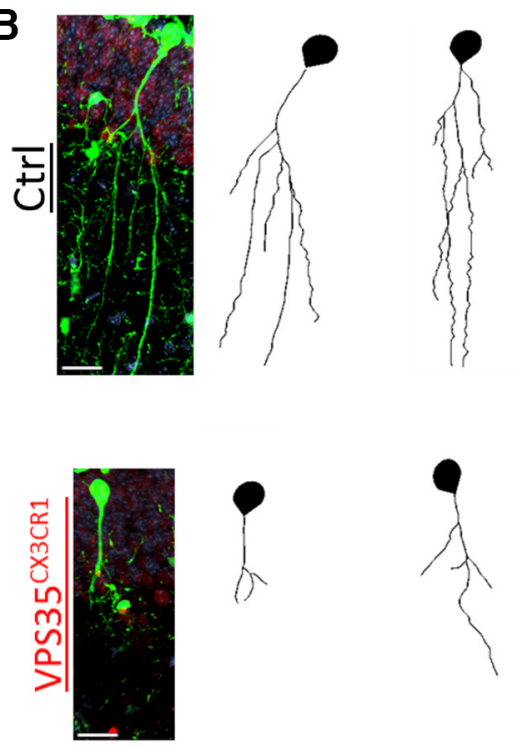

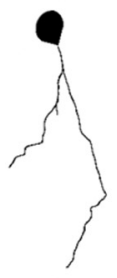

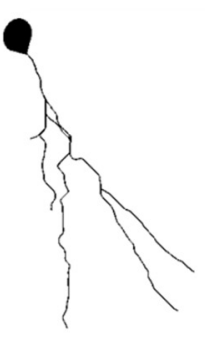
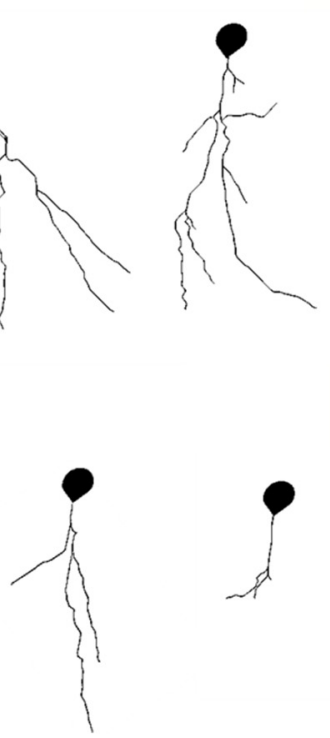

D Total Dendritic Process Length

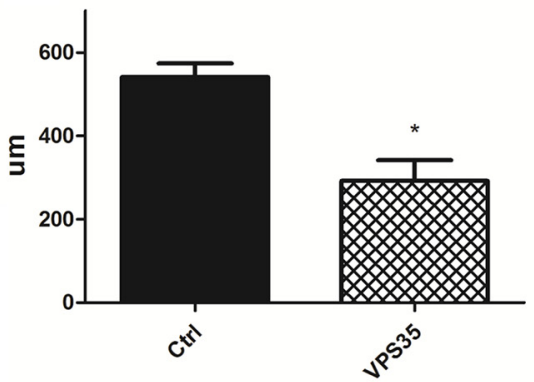

\section{E Total \# Branches}

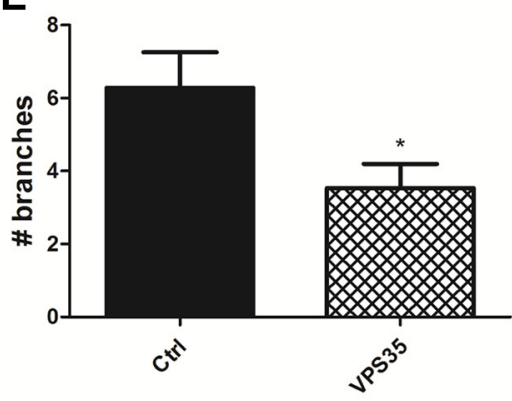

C

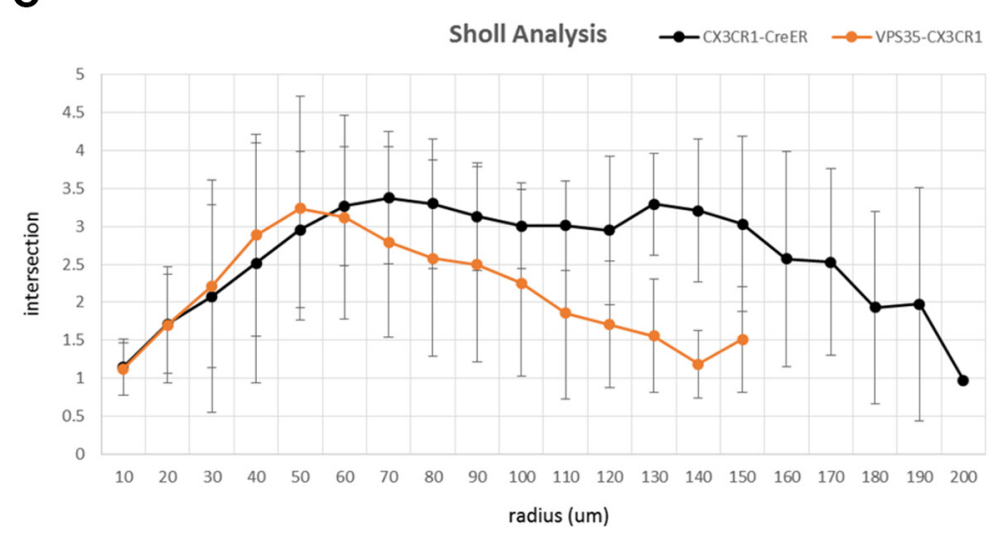

F

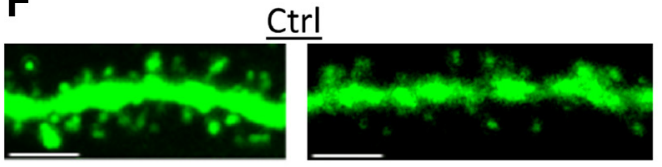

VPS35 $5^{\text {CX3CR1 }}$
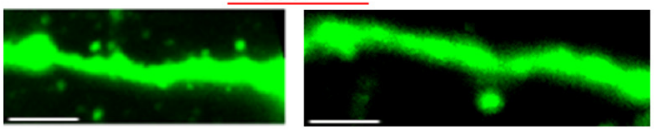

G

Spine Density

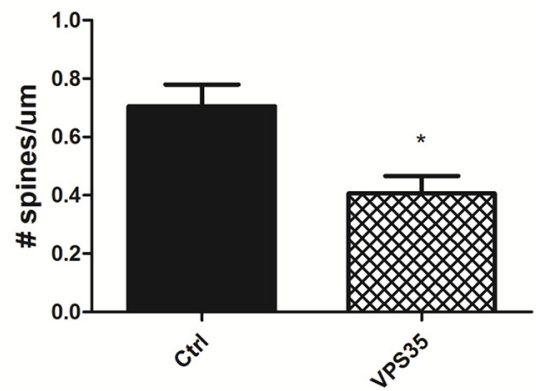

Figure 10. Neurodegenerative-like morphology of newborn neurons in VPS35 ${ }^{C \times 3 C R 1}$ DGS. $A$, Schematic of timeline for stereotaxic injection of a GFP-expressing retroviral vector into the DG to selectively label dividing cells. B, Representative images of GFP+ neurons and tracings. Scale bar, $20 \mu \mathrm{m}$. $\boldsymbol{F}, \mathbf{G}$, GFP + neurons in DGs of VPS35 ${ }^{\text {CX3CR1 }}$ mice exhibited decreased dendritic spine density (Student's $t$ test, $n=10$ secondary branches from 2 animals per group, $p<0.05)$. C, Sholl analysis indicates decreased number of intersections in GFP + neurons in the DGs of VPS35 ${ }^{C \times 3 C R 1}$ mice. D, E, GFP + neurons in VPS35 ${ }^{\mathrm{CX} C \mathrm{CR} 1}$ mice were found to have decreased total length of processes $(p=0.0028)$ and total number of branches $(p=0.027 ;$ Student's t test, $n=20$ neurons from 2 animals per group). $F, G, G F P+$ neurons in DGs of VPS $35^{\text {CX3CR1 }}$ mice exhibited decreased dendritic spine density. Scale bar, $2.5 \mu \mathrm{m}$ (Student's unpaired $t$ test, $n=10$ secondary branches from 2 animals per group, $p=0.0023)$. For all analyses, statistical significance $\left({ }^{*} p \leq 0.05\right)$.

trols (Fig. $11 \mathrm{~J}, \mathrm{~K}$ ). This signifies a potential direct targeting of postsynaptic material by VPS35 ${ }^{\mathrm{CX} 3 \mathrm{CR} 1}$ microglia, which potentially is a mechanism through which microglial VPS35 loss of function contributes to the observed in vivo phenotype of hippocampal newborn neuronal spine/synapse deficit.
When considered together, these data (Figs. 8-11) suggest that the reduction of $\mathrm{DCX}^{+}$neurons and the degenerative morphology of newborn neurons observed in the VPS35 ${ }^{\mathrm{CX} 3 \mathrm{CR} 1}$ hippocampus could be due to a combination of both defective neuronal differentiation and exacerbated pruning of postsynaptic elements. 


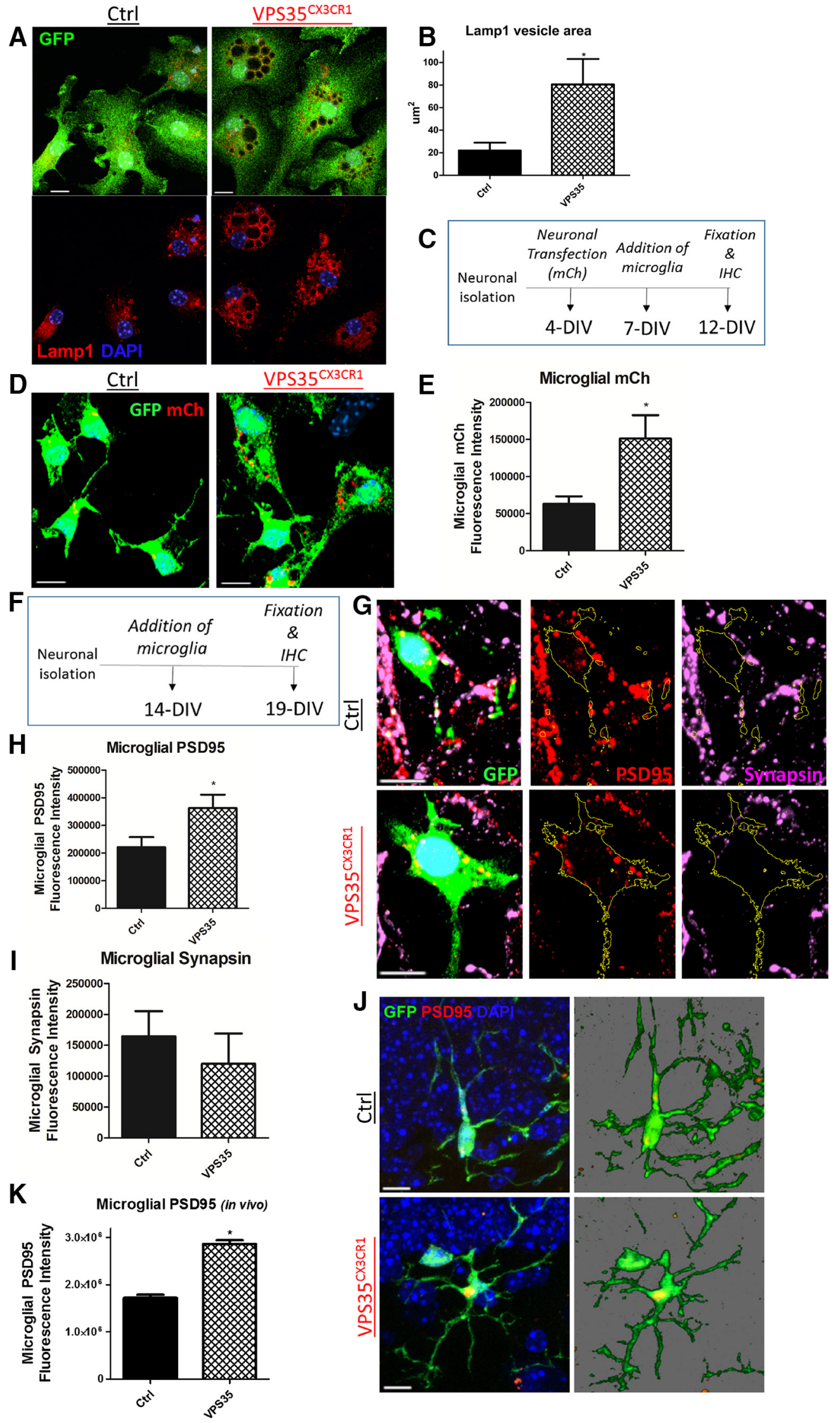

Figure 11. Increased microglial engulfment of postsynaptic elements following microglial VPS35 loss of function. $A, B$, Primary microglia isolated from adult VPS35 $5^{\text {CXCR1 }}$ mice exhibit grossly enlarged vacuolar structures. Scale bar, $10 \mu \mathrm{m}$ (Student's unpaired $t$ test, $n=7-10$ microglia per group, $p=0.0059)$. C $E$, VPS35 ${ }^{\text {CXCR1 }}$ primary microglia cocultured with primary cortical neurons transfected with $\mathrm{mCh}$ construct exhibit increased uptake of $\mathrm{mCh}+$ neuronal debris. Scale bar, $10 \mu \mathrm{m}$ (Student's unpaired $t$ test, $n=8$ microglia per group, (Figure legend continues.) 


\section{Impaired long-term memory and depression-like behavior following microglial VPS35 depletion}

To determine whether microglial VPS35 depletion functionally affects VPS3 $35^{\text {CX3CR1 }}$ mouse behavior, a behavioral panel was performed to assess behavioral phenotype (Fig. 12A). An open-field test was first carried out to analyze locomotor activity and assess any proclivity for anxiety. No difference between control and VPS35 ${ }^{\text {CX } 3 C R 1}$ mice was observed in distance traveled, velocity, or time spent in the center (Fig. 12B-E), suggesting normal locomotor activity without obvious anxiety in the mutant. Mice were then subjected to the $\mathrm{Y}$-maze test to assess spatial recognition (Fig. 12F). Again, no difference in number of alternations was observed (Fig. 12G), indicating that spatial recognition in the mutant mice was comparable to that of controls. We further assessed recognition memory by the novel-object recognition paradigm at $30 \mathrm{~min}, 120 \mathrm{~min}$, and $48 \mathrm{~h}$ to assess both short-term and long-term memory (Fig. 12H). A slight reduction (not significant) in recognition index $(p=0.06)$ was observed after 30 and $120 \mathrm{~min}$ following the training session (Fig. 12I). A significant reduction in recognition was observed after $48 \mathrm{~h}$, suggesting impaired long-term memory following microglial VPS35 depletion (Fig. 12I).

Finally, we performed sucrose-preference, forced-swim, and tail-suspension tests to measure depressive behavior (Fig. 12 J,L). Decreased sucrose preference in VPS35 ${ }^{\text {CX3CR1 }}$ mice suggests a reduced drive for pleasure-seeking activity (Fig. 12J). The time that VPS35 ${ }^{\text {CX3CR1 }}$ mice spent immobile during tail suspension was significantly increased (Fig. $12 \mathrm{~K}$ ), suggesting a tendency of VPS35 ${ }^{\text {CX } 3 \text { CR } 1 ~ m i c e ~ f o r ~ d e p r e s s i v e ~ b e h a v i o r . ~ W h i l e ~ t h e r e ~ w a s ~ n o ~}$ significant difference in time spent immobile during the forcedswim test, VPS35 ${ }^{\text {CX3CR1 }}$ mice did exhibit a trend toward increased immobility (Fig. 12L). Together, these results demonstrate depression-like behavior and impaired long-term memory in VPS35 ${ }^{\mathrm{CX} 3 \mathrm{CR} 1}$ mice.

\section{Discussion}

The roles of dysfunctional microglia and associated neuroinflammation have been highly implicated in neurodegenerative disease pathology, but evidence regarding the role, if any, that microglial VPS35 might play in the pathogenesis of $\mathrm{AD}$ is limited. To address this issue, we developed an in vivo mouse model of microglialspecific VPS35 loss of function to assess microglial VPS35's function in the adult CNS and how its dysregulation might contribute to neurodegenerative disease pathology. Based upon this model, our findings provide a novel, microglial-specific role for VPS35, in which microglial VPS35 is essential for not only preventing microglial activation in vivo, but also for maintaining adult hippocampal neurogenesis and promoting the development of newborn neurons in the hippocampus.

Using this in vivo mouse model of microglial VPS5 loss of function, our initial observations showed that loss of VPS35 from mature microglia in vivo increases microglial density in a regionalspecific manner. Microglia have been shown to proliferate and

$\leftarrow$

(Figure legend continued.) $p=0.0187) . F-I$, VPS35 ${ }^{\text {CX3CR1 }}$ primary microglia cocultured with primary cortical neurons exhibit increased engulfment of PSD95 + postsynaptic material ( $p=$ 0.0323 ), without any significant uptake of synapsin + presynaptic material $(p=0.4965)$. Scale bar, $10 \mu \mathrm{m}$ (Student's unpaired $t$ test, $n=9$ microglia per group). J, $\boldsymbol{K}, \mathrm{VPS} 35^{\mathrm{CX} 3 \mathrm{CR} 1}$ hippocampal microglia display increased engulfment of PSD95 + postsynaptic material in vivo as exhibited by high-resolution confocal microscopy analysis of GFP:PSD95 coimmunofluorescence. Scale bar, $50 \mu \mathrm{m}$ (Student's unpaired $t$ test, $n=7, p=0.0002$ ). For all analyses, statistical significance $\left.{ }^{*} p \leq 0.05\right)$. differentiate from CNS nestin-positive progenitor cells (Elmore et al., 2014), so while we saw no increase in microglial proliferation within the hippocampus, there remains the possibility that increased microglia in the hippocampus resulted from either increased differentiation of progenitor cells into microglia or migration of microglia from neighboring regions.

CX3CR1 is not a microglial-specific marker as it is also expressed by other myeloid cells, and peripheral macrophages have been observed to invade neuronal tissue under pathological conditions. Infiltration of peripheral macrophages has been shown to contribute to elevated levels of microglial activity as well as to neurodegenerative disease pathology (for review, see Rezai-Zadeh et al., 2009; Sevenich, 2018). Our observed increase of $\mathrm{GFP}^{+}$: Tmem $119^{-}$cell density (in addition to an increased density of $\mathrm{GFP}^{+}$:Tmem $119^{+}$cells) suggests the possibility of an increase of peripheral macrophages (or other cells of myeloid origin) in the

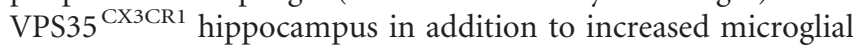
cell density.

Microglial retromer loss of function was also shown to upregulate microglial activity within the hippocampus in a manner consistent with reports of proinflammatory activity. It would be beneficial for future studies to further investigate potential mechanisms underlying our observations by determining the inflammatory profile of microglia following VPS35 depletion and how increased activity affects the overall function and nature of VPS35-depleted microglia. Such investigations could help identify potential mechanistic players that might contribute to the observed phenotype of VPS35 ${ }^{\text {CX3CR1 }}$ mice.

Disturbances to the local pool of hippocampal microglia cooccurred with disrupted hippocampal neurogenesis, as observed by an increase of proliferating NSCs/NPCs, impaired cell-cycle exit, a decrease in immature neurons, abnormal dendritic morphology of newborn neurons, and aberrant microglial engulfment of synaptic material. It is of interest to note that recent advances implicate a role for microglia in adult hippocampal neurogenesis, a phenomenon that occurs primarily in the SGZ and that can be impaired by dysfunctional microglia and elevated proinflammatory factors (Ekdahl et al., 2003; Monje et al., 2003; Sierra et al., 2010, 2013). While microglia have been identified as contributors to the regulation of adult hippocampal neurogenesis, the full extent of this regulation and its mechanisms remain to be elucidated. Our findings implicate a regulatory role of microglia during hippocampal neurogenesis. The exact nature of this novel role of microglia and the mechanisms through which VPS35-deficient microglia disturb hippocampal neurogenesis will require further investigation.

It is important to note that disturbed hippocampal neurogenesis has been implicated as an early event in the course of AD pathogenesis (Jin et al., 2004; Ziabreva et al., 2006). Also, in AD mouse models, impaired hippocampal neurogenesis compromises hippocampal function and contributes to cognitive deficits (Rodríguez et al., 2008; Demars et al., 2010; Hamilton et al., 2010; Lazarov and Marr, 2010, 2013). While reports regarding the exact nature and extent of disrupted adult hippocampal neurogenesis in $\mathrm{AD}$ vary, the overall consensus is that such events play a role in the early stages of $\mathrm{AD}$ progression. This study presents a behavioral phenotype of VPS35 ${ }^{\mathrm{CX} 3 \mathrm{CR} 1}$ mice concurrent with the literature describing behavioral impairments that co-occur with impaired hippocampal neurogenesis. Depressive behavior is a classic hallmark of disrupted hippocampal neurogenesis (Sahay and Hen, 2007; Mateus-Pinheiro et al., 2013) and long-term memory has shown to be reliant upon hippocampal neurogenesis, with deficiencies 


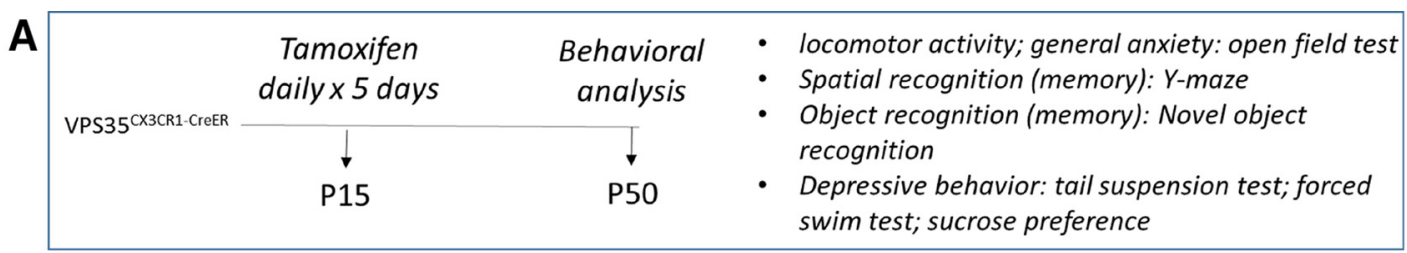

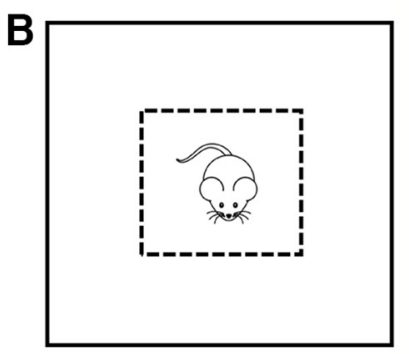

\section{C}

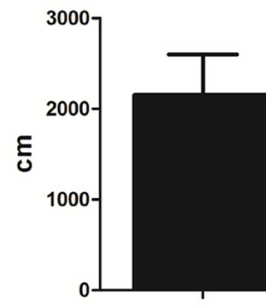

OFT Total Distance

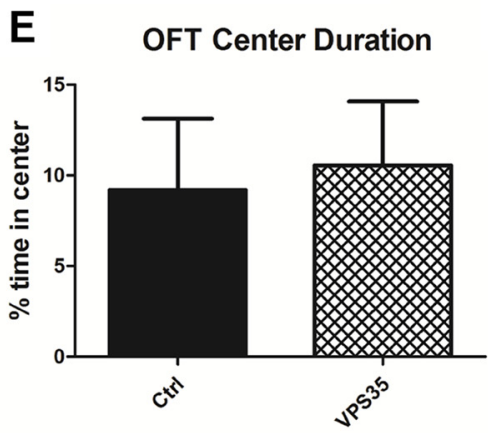

H

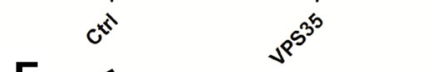

F

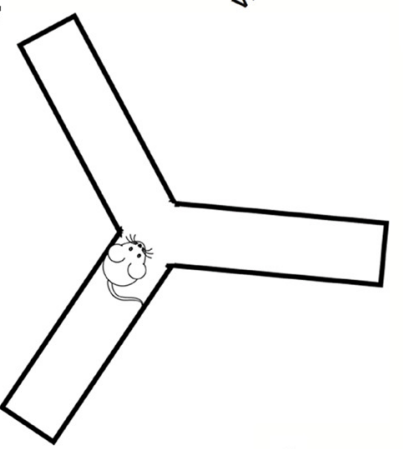

I
D

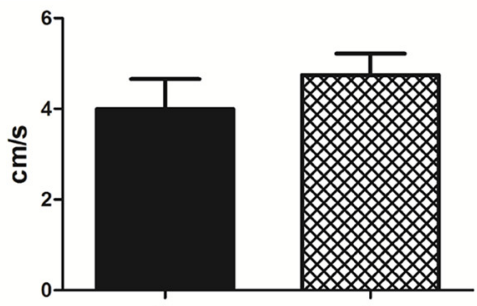

G
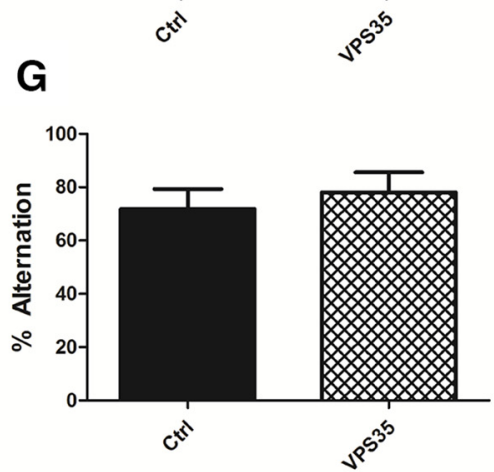

Novel Object Recognition
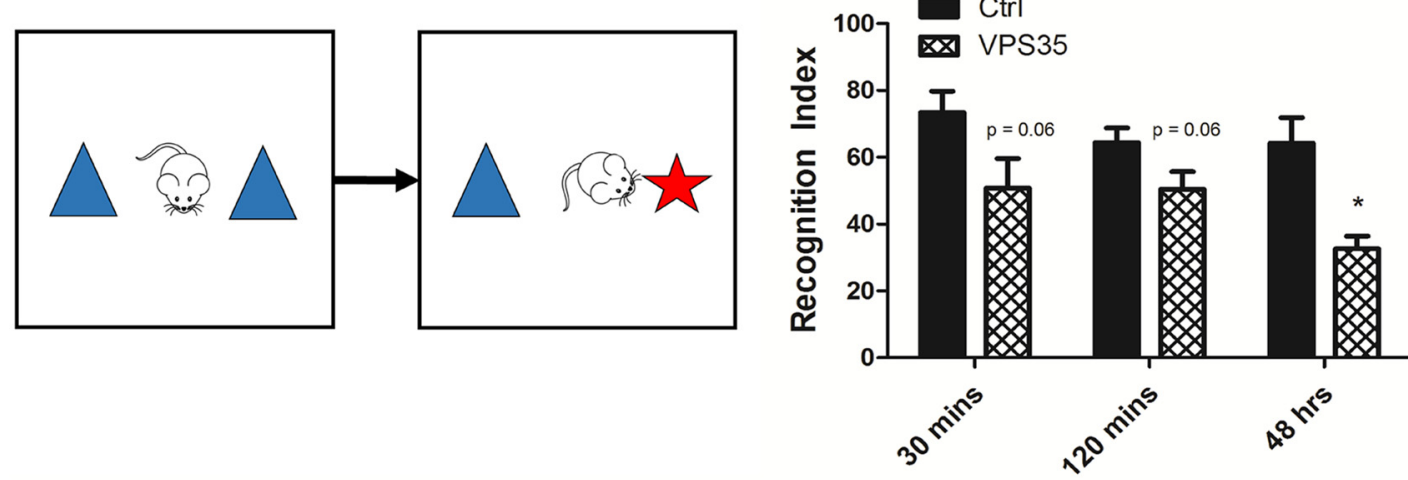

J

Sucrose Preference K

Forced Swim

L Tail Suspension Test
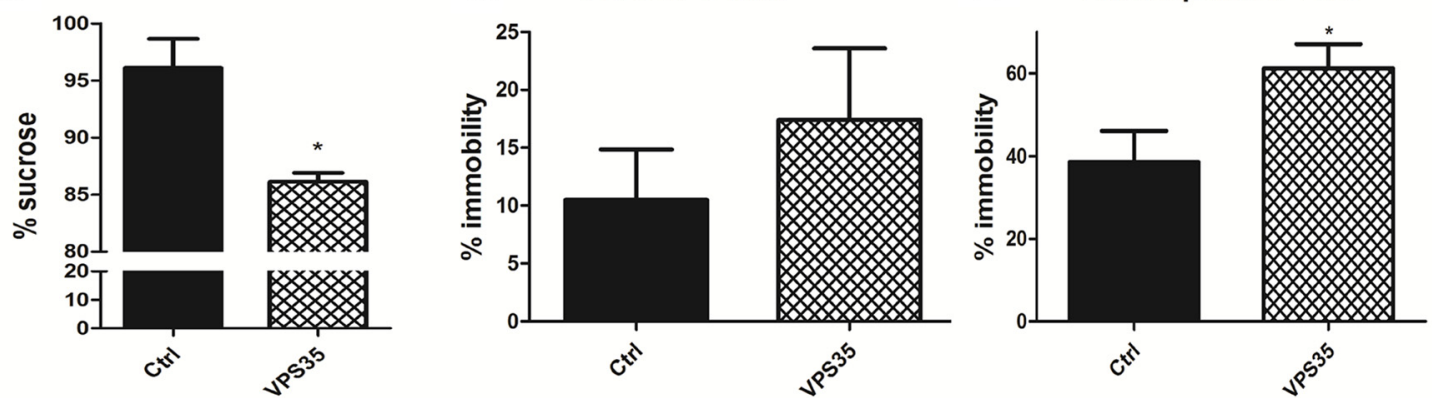

Figure 12. Behavioral phenotypes of the VPS35 ${ }^{\mathrm{CX} 3 \mathrm{CR} 1}$ mouse. $\boldsymbol{A}$, Outline of behavioral analysis experimental design. $\boldsymbol{B}-\boldsymbol{E}$, Open-field test locomotor activity $(\boldsymbol{C}, \boldsymbol{D})$ and anxiety-related behavior (E) are not altered in VPS35CX3CR1 mice as gauged by total distance $(p=0.285)$, mean velocity $(p=0.3695)$, and time spent in the center $(p=0.8)$. $\boldsymbol{F}, \mathbf{G}$, No significant difference was observed in Y-maze performance $(p=0.5586)$, suggesting that spatial memory is not impaired in VPS35 ${ }^{\mathrm{CX} 3 C \mathrm{CR} 1}$ mice. $\boldsymbol{H}, \boldsymbol{I}$, Novel-object recognition suggests a slight impairment in VPS35 $5^{\mathrm{CX} 3 \mathrm{CR} 1}$ recognition memory as indicated by a $p$ value of 0.06 and a recognition index of $50 \% 30$ and $120 \mathrm{~min}$ following initial exposure and a significant impairment in long-term memory (48 h after exposure, $p=$ $0.0023) . J-L$, Depressive model behavioral testing revealed tendency toward depressive behavior in VPS35 ${ }^{\mathrm{CX} C \mathrm{CR} 1}$ mice. $I$, Sucrose preference is significantly lower in VPS35 ${ }^{\mathrm{CX} C \mathrm{CR} 1}$ mice $(p=0.0019)$ than in controls, suggesting a reduced tendency VPS35 ${ }^{\mathrm{CX} C \mathrm{R} 1}$ pleasure-seeking behavior. J, Time spent immobile during tail suspension is significantly higher in VPS35 ${ }^{\mathrm{CX} 3 \mathrm{CR} 1}$ mice $(p=0.0275)$. $\boldsymbol{K}$, Forced-swim test shows a trend toward increased time spent immobile by VPS35 ${ }^{\mathrm{CX} 3 \mathrm{R} 1}$ mice, but not significantly $(p=0.1882)$. All tests were statistically analyzed by Student's $t$ test, except for novel-object recognition, which was analyzed by one-way ANOVA $(n=8)$. For all analyses, statistical significance $\left({ }^{*} p \leq 0.05\right)$. 
observed following impaired hippocampal neurogenesis (BruelJungerman et al., 2005; Sahay et al., 2011; Pan et al., 2012).

$\mathrm{AD}$ pathogenesis first begins to manifest in the Ec-Ctx, and Ec-Ctx VPS35 levels are downregulated in AD compared with VPS35 levels in the DG (Small et al., 2005). As our data indicated increased microglial density in the Ec-Ctx, it can be hypothesized that VPS35 ${ }^{\mathrm{CX} 3 \mathrm{CR1}}$ microglial activity in this region would be similar to observations made in the hippocampus and might affect Ec-Ctx dendritic morphology. Ec-Ctx stimulation has been shown to promote the proliferation and neurogenesis of newborn neurons in the DG (Stone et al., 2011), so it is feasible the neurogenic abnormalities observed in VPS35 ${ }^{\mathrm{CX} 3 \mathrm{CR} 1}$ mice could be attributed to functional impairment of the Ec-Ctx. Additionally, newborn hippocampal neurons in the DG integrate into the hippocampal circuitry to send axonal projections to hippocampal CA3 neurons (Markakis and Gage, 1999), so it follows that hippocampal circuitry might be adversely regulated in VPS35 ${ }^{\text {CX3CR1 }}$ mice. Further investigations into the functional consequences of microglial VPS35 loss of function should explore the functionality of both Ec-Ctx and hippocampal circuitry.

In concurrence with previous reports of microglial VPS35 regulation of phagocytic receptors (Lucin et al., 2013; Yin et al., 2016), our studies implicate microglial VPS35's function in regulating microglial phagocytic activity. It is important to note here the relevance of these findings, as microglial depletion of C9orf72 [a regulator of endosomal trafficking (Farg et al., 2014)] results in similar enlargement of LAMP1 ${ }^{+}$vesicles, as observed in VPS35 ${ }^{\text {CX3CR1 }}$ microglia (O'Rourke et al., 2016), and microglial depletion of TDP-43 [also a regulator of endosomal trafficking (Schwenk et al., 2016)] leads to increased levels of lysosomal markers, which coincides with excessive synaptic pruning (Paolicelli et al., 2017). In addition to enlarged LAMP1 ${ }^{+}$vacuolar-like structures, our data suggest that VPS35-depleted microglia exhibit upregulated engulfment of postsynaptic processes, which is possibly one mechanism through which microglial VPS35 loss of function acts to affect the neurodegenerative phenotype observed in the VPS35 ${ }^{\text {CX3CR1 }}$ hippocampus. It is important to note that our results do not exclude the possibility that cocultured VPS35-deficient microglia may take up neuronal material as a result of neuronal death via indirect consequences of microglial VPS35 loss of function (as opposed to direct phagocytosis of live neuronal processes). It is also possible that the increased $\mathrm{mCh}$ and PSD95 in VPS35 mutant microglia are due to impaired degradation of these proteins in the mutant microglial lysosomes. During embryonic development and in the developing postnatal brain, microglia participate in synaptic pruning via complement receptor-mediated phagocytosis of synaptic elements, with recent evidence suggesting microglia-mediated synaptic pruning continues throughout adulthood via similar mechanisms (Stevens et al., 2007; Tremblay et al., 2010; Paolicelli et al., 2011; Schafer et al., 2012). Due to the mounting evidence that complement receptor-mediated phagocytosis plays a role in synaptic pruning and integration of adult neuronal processes, it will be of interest to address the role of microglial VPS35 in the regulation of synaptic pruning and to address the issue of how microglial VPS35 loss of function might contribute to disease pathology through the phagocytic activity of microglia upon dendritic processes.

The findings of this study suggest a region-specific effect of microglial VPS35 depletion, as well as the potential for an agespecific effect. Further studies should investigate the consequences of microglial VPS35 depletion in an age-specific and regional-specific manner. Of primary interest is the substantia nigra (SN), in which we also observed increased microglial density. Since dysfunction of VPS35 is implicated in PD, it is necessary to also investigate whether VPS35-deficient microglia affect functional and/or morphological changes in this region. Neurogenesis has been documented in the SN (Zhao et al., 2003; Yoshimi et al., 2005), so investigations into whether $\mathrm{SN}$ neurogenesis and its functional results are altered in VPS35 ${ }^{\mathrm{CX} 3 \mathrm{CR} 1}$ mice would be intriguing. Unreported data from VPS35 ${ }^{\text {CX3CR1 }}$ mice suggested that the SN might also present a neurodegenerative morphological phenotype (examined via Golgi staining of SN neurons), so mechanisms underlying microglial VPS35-mediated regulation of this region could contribute to our understanding of VPS35's role in PD pathology.

The findings presented here provide the first in vivo evidence that VPS35/retromer is essential for maintaining microglial homeostasis, and when microglial retromer mechanics are disrupted, the effects can be observed not only in microglia themselves, but in surrounding neurons and critical neurogenic processes. Uncovering the molecular mechanisms underlying disease pathology is the first step toward disease prevention and discovery of cures. Retromer and VPS35 have been implicated as molecular mediators in neurodegenerative pathology, but the exact mechanisms through which retromer dysfunction imparts disease pathology have yet to be elucidated. Identification of cell-specific mechanisms underlying disease pathology is an important step for improving the experimental models used to investigate disease. By further identifying retromer-associated mediators of the neurodegenerative pathway, we hope to establish new methods for early detection of disease onset, preventative measures to counter pathological mechanisms, and therapeutic options to target the retromer pathway.

\section{References}

Bennett ML, Bennett FC, Liddelow SA, Ajami B, Zamanian JL, Fernhoff NB, Mulinyawe SB, Bohlen CJ, Adil A, Tucker A, Weissman IL, Chang EF, Li G, Grant GA, Hayden Gephart MG, Barres BA (2016) New tools for studying microglia in the mouse and human CNS. Proc Natl Acad Sci U S A 113:E1738-E1746. CrossRef Medline

Bonifacino JS (2014) Adaptor proteins involved in polarized sorting. J Cell Biol 204:7-17. CrossRef Medline

Bruel-Jungerman E, Laroche S, Rampon C (2005) New neurons in the dentate gyrus are involved in the expression of enhanced long-term memory following environmental enrichment. Eur J Neurosci 21:513-521. CrossRef Medline

Cryan JF, Markou A, Lucki I (2002) Assessing antidepressant activity in rodents: recent developments and future needs. Trends Pharmacol Sci 23:238-245. CrossRef Medline

Demars M, Hu YS, Gadadhar A, Lazarov O (2010) Impaired neurogenesis is an early event in the etiology of familial Alzheimer's disease in transgenic mice. J Neurosci Res 88:2103-2117. CrossRef Medline

Ekdahl CT, Claasen JH, Bonde S, Kokaia Z, Lindvall O (2003) Inflammation is detrimental for neurogenesis in adult brain. Proc Natl Acad Sci U S A 100:13632-13637. CrossRef Medline

Elmore MR, Najafi AR, Koike MA, Dagher NN, Spangenberg EE, Rice RA, Kitazawa M, Matusow B, Nguyen H, West BL, Green KN (2014) Colony-stimulating factor 1 receptor signaling is necessary for microglia viability, unmasking a microglia progenitor cell in the adult brain. Neuron 82:380-397. CrossRef Medline

Farg MA, Sundaramoorthy V, Sultana JM, Yang S, Atkinson RA, Levina V, Halloran MA, Gleeson PA, Blair IP, Soo KY, King AE, Atkin JD (2014) (2014) C9ORF72, implicated in amytrophic lateral sclerosis and frontotemporal dementia, regulates endosomal trafficking. Hum Mol Genet 23:3579-3595. CrossRef Medline

Hamilton LK, Aumont A, Julien C, Vadnais A, Calon F, Fernandes KJ (2010) Widespread deficits in adult neurogenesis precede plaque and tangle formation in the 3xTg mouse model of Alzheimer's disease. Eur J Neurosci 32:905-920. CrossRef Medline

Hierro A, Rojas AL, Rojas R, Murthy N, Effantin G, Kajava AV, Steven AC, Bonifacino JS, Hurley JH (2007) Functional architecture of the retromer cargo-recognition complex. Nature 449:1063-1067. CrossRef Medline

Hirasawa T, Ohsawa K, Imai Y, Ondo Y, Akazawa C, Uchino S, Kohsaka S 
(2005) Visualization of microglia in living tissues using Iba1-EGFP transgenic mice. J Neurosci Res 81:357-362. CrossRef Medline

Jiang M, Chen G (2006) High Ca2+-phosphate transfection efficiency in low-density neuronal cultures. Nat Protocols 1:695-700. CrossRef Medline

Jin K, Peel AL, Mao XO, Xie L, Cottrell BA, Henshall DC, Greenberg DA (2004) Increased hippocampal neurogenesis in Alzheimer's disease. Proc Natl Acad Sci U S A 101:343-347. CrossRef Medline

Lazarov O, Marr RA (2010) Neurogenesis and Alzheimer's disease: at the crossroads. Exp Neurol 223:267-281. CrossRef Medline

Lazarov O, Marr R (2013) Of mice and men: neurogenesis, cognition and Alzheimer's disease. Front Aging Neurosci 5:43. CrossRef Medline

Liu W, Tang FL, Erion J, Xiao H, Ye J, Xiong WC (2014) Vps35 haploinsufficiency results in degenerative-like deficit in mouse retinal ganglion neurons and impairment of optic nerve injury-induced gliosis. Mol Brain 7:10. CrossRef Medline

Lucin KM, O’Brien CE, Bieri G, Czirr E, Mosher KI, Abbey RJ, Mastroeni DF, Rogers J, Spencer B, Masliah E, Wyss-Coray T (2013) Microglial beclin 1 regulates retromer trafficking and phagocytosis and is impaired in Alzheimer's disease. Neuron 79:873-886. CrossRef Medline

Markakis EA, Gage FH (1999) Adult-generated neurons in the dentate gyrus send axonal projections to field CA3 and are surrounded by synaptic vesicles. J Comp Neurol 406:449-460. CrossRef Medline

Mateus-Pinheiro A, Pinto L, Bessa JM, Morais M, Alves ND, Monteiro S, Patrício P, Almeida OF, Sousa N (2013) Sustained remission from depressive-like behavior depends on hippocampal neurogenesis. Transl Psychiatry 3:e210. CrossRef Medline

Monje ML, Toda H, Palmer TD (2003) Inflammatory blockade restores adult hippocampal neurogenesis. Science 302:1760-1765. CrossRef Medline

Muhammad A, Flores I, Zhang H, Yu R, Staniszewski A, Planel E, Herman M, Ho L, Kreber R, Honig LS, Ganetzky B, Duff K, Arancio O, Small SA (2008) Retromer deficiency observed in Alzheimer's disease causes hippocampal dysfunction, neurodegeneration, and $\mathrm{A} \beta$ accumulation. Proc Natl Acad Sci U S A 105:7327-7332. CrossRef Medline

Munsie LN, Milnerwood AJ, Seibler P, Beccano-Kelly DA, Tatarnikov I, Khinda J, Volta M, Kadgien C, Cao LP, Tapia L, Klein C, Farrer MJ (2015) Retromer-dependent neurotransmitter receptor trafficking to synapses is altered by the Parkinson's disease VPS35 mutation p.D620N. Hum Mol Genet 24:1691-1703. CrossRef Medline

Nielsen MS, Gustafsen C, Madsen P, Nyengaard JR, Hermey G, Bakke O, Mari M, Schu P, Pohlmann R, Dennes A, Petersen CM (2007) Sorting by the cytoplasmic domain of the amyloid precursor protein binding receptor SorLA. Mol Cell Biol 27:6842-6851. CrossRef Medline

Nothwehr SF, Bruinsma P, Strawn LA (1999) Distinct domains within Vps35p mediate the retrieval of two different cargo proteins from the yeast prevacuolar/endosomal compartment. Mol Biol Cell 10:875-890. CrossRef Medline

O’Rourke JG, Bogdanik L, Yáñez A, Lall D, Wolf AJ, Muhammad AK, Ho R, Carmona S, Vit JP, Zarrow J, Kim KJ, Bell S, Harms MB, Miller TM, Dangler CA, Underhill DM, Goodridge HS, Lutz CM, Baloh RH (2016) C9orf72 is required for proper macrophage and microglial function in mice. Science 351:1324-1329. CrossRef Medline

Pan YW, Chan GC, Kuo CT, Storm DR, Xia Z (2012) Inhibition of adult neurogenesis by inducible and targeted deletion of ERK5 MAP kinase specifically in adult neurogenic regions impairs contextual fear memory extinction and remote fear memory. J Neurosci 32:6444-6455. CrossRef Medline

Paolicelli RC, Bolasco G, Pagani F, Maggi L, Scianni M, Panzanelli P, Giustetto M, Ferreira TA, Guiducci E, Dumas L, Ragozzino D, Gross CT (2011) Synaptic pruning by microglia is necessary for normal brain development. Science 333:1456-1458. CrossRef Medline

Paolicelli RC, Jawaid A, Henstridge CM, Valeri A, Merlini M, Robinson JL, Lee EB, Rose J, Appel S, Lee VM, Trojanowski JQ, Spires-Jones T, Schulz PE, Rajendran L (2017) TDP-43 depletion in microglia promotes amyloid clearance but also induces synapse loss. Neuron 95:297-308.e6. CrossRef Medline

Parkhurst CN, Yang G, Ninan I, Savas JN, Yates JR 3rd, Lafaille JJ, Hempstead BL, Littman DR, Gan WB (2013) Microglia promote learning-dependent synapse formation through brain-derived neurotrophic factor. Cell 155:15961609. CrossRef Medline

Prasad BC, Clark SG (2006) Wnt signaling establishes anteroposterior neuronal polarity and requires retromer in C. elegans. Development 133:17571766. CrossRef Medline
Rezai-Zadeh K, Gate D, Town T (2009) CNS infiltration of peripheral immune cells: D-day for neurodegenerative disease? J Neuroimmune Pharmacol 4:462-475. CrossRef Medline

Rodríguez JJ, Jones VC, Tabuchi M, Allan SM, Knight EM, LaFerla FM, Oddo S, Verkhratsky A (2008) Impaired adult neurogenesis in the dentate gyrus of a triple transgenic mouse model of Alzheimer's disease. PLoS One 3:e2935. CrossRef Medline

Sahay A, Hen R (2007) Adult hippocampal neurogenesis in depression. Nat Neurosci 10:1110-1115. CrossRef Medline

Sahay A, Scobie KN, Hill AS, O'Carroll CM, Kheirbek MA, Burghardt NS, Fenton AA, Dranovsky A, Hen R (2011) Increasing adult hippocampal neurogenesis is sufficient to improve pattern separation. Nature 472:466470. CrossRef Medline

Satoh J, Kino Y, Asahina N, Takitani M, Miyoshi J, Ishida T, Saito Y (2016) TMEM119 marks a subset of microglia in the human brain. Neuropathology 36:39-49. CrossRef Medline

Schafer DP, Lehrman EK, Kautzman AG, Koyama R, Mardinly AR, Yamasaki R, Ransohoff RM, Greenberg ME, Barres BA, Stevens B (2012) Microglia sculpt postnatal neural circuits in an activity and complementdependent manner. Neuron 74:691-705. CrossRef Medline

Schwenk BM, Hartmann H, Serdaroglu A, Schludi MH, Hornburg D, Meissner F, Orozco D, Colombo A, Tahirovic S, Michaelsen M, Schreiber F, Haupt S, Peitz M, Brüstle O, Küpper C, Klopstock T, Otto M, Ludolph AC, Arzberger T, Kuhn PH, et al (2016) TDP-43 loss of function inhibits endosomal trafficking and alters trophic signaling in neurons. EMBO J 35:2350-2370. CrossRef Medline

Seaman MN, McCaffery JM, Emr SD (1998) A membrane coat complex essential for endosome-to-golgi retrograde transport in yeast. J Cell Biol 142:665-681. CrossRef Medline

Sevenich L (2018) Brain-resident microglia and blood-borne macrophages orchestrate central nervous system inflammation in neurodegenerative disorders and brain cancer. Front Immunol 9:697. CrossRef Medline

Sierra A, Encinas JM, Deudero JJ, Chancey JH, Enikolopov G, OverstreetWadiche LS, Tsirka SE, Maletic-Savatic M (2010) Microglia shape adult hippocampal neurogenesis through apoptosis-coupled phagocytosis. Cell Stem Cell 7:483-495. CrossRef Medline

Sierra A, Abiega O, Shahraz A, Neumann H (2013) Janus-faced microglia: beneficial and detrimental consequences of microglial phagocytosis. Front Cell Neurosci 7:6. CrossRef Medline

Small SA, Petsko GA (2015) Retromer in Alzheimer disease, Parkinson disease and other neurological disorders. Nat Rev Neurosci 16:126-132. CrossRef Medline

Small SA, Kent K, Pierce A, Leung C, Kang MS, Okada H, Honig L, Vonsattel JP, Kim TW (2005) Model-guided microarray implicates the retromer complex in Alzheimer's disease. Ann Neurol 58:909-919. CrossRef Medline

Stevens B, Allen NJ, Vazquez LE, Howell GR, Christopherson KS, Nouri N, Micheva KD, Mehalow AK, Huberman AD, Stafford B, Sher A, Litke AM, Lambris JD, Smith SJ, John SW, Barres BA (2007) The classical complement cascade mediates CNS synapse elimination. Cell 131:1164-1178. CrossRef Medline

Stone SS, Teixeira CM, Devito LM, Zaslavsky K, Josselyn SA, Lozano AM, Frankland PW (2011) Stimulation of entorhinal cortex promotes adult neurogenesis and facilitates spatial memory. J Neurosci 31:13469-13484. CrossRef Medline

Tang FL, Erion JR, Tian Y, Liu W, Yin DM, Ye J, Tang B, Mei L, Xiong WC (2015a) VPS35 in dopamine neurons is required for endosome-to-Golgi retrieval of Lamp2a, a receptor of chaperone-mediated autophagy that is critical for $\alpha$-synuclein degradation and prevention of pathogenesis of Parkinson's disease. J Neurosci 35:10613-10628. CrossRef Medline

Tang FL, Liu W, Hu JX, Erion JR, Ye J, Mei L, Xiong WC (2015b) VPS35 deficiency or mutation causes dopaminergic neuronal loss by impairing mitochondrial fusion and function. Cell Rep 12:1631-1643. CrossRef Medline

Tian Y, Tang FL, Sun X, Wen L, Mei L, Tang BS, Xiong WC (2015) VPS35deficiency results in an impaired AMPA receptor trafficking and decreased dendritic spine maturation. Molecular Brain 8:70. CrossRef Medline

Tremblay MÈ, Lowery RL, Majewska AK (2010) Microglial interactions with synapses are modulated by visual experience. PLoS Biol 8:e1000527. CrossRef Medline

Ueda N, Tomita T, Yanagisawa K, Kimura N (2016) Retromer and Rab2dependent trafficking mediate PS1 degradation by proteasomes in endocytic disturbance. J Neurochem 137:647-658. CrossRef Medline 
Vergés M (2016) Retromer in polarized protein transport. Int Rev Cell Mol Biol 323:129-179. CrossRef Medline

Wang CL, Tang FL, Peng Y, Shen CY, Mei L, Xiong WC (2012) VPS35 regulates developing mouse hippocampal neuronal morphogenesis by promoting retrograde trafficking of BACE1. Biol Open 1:1248-1257. CrossRef Medline

Wang W, Wang X, Fujioka H, Hoppel C, Whone AL, Caldwell MA, Cullen PJ, Liu J, Zhu X (2016) Parkinson's disease-associated mutant VPS35 causes mitochondrial dysfunction by recycling DLP1 complexes. Nat Med 22:5463. CrossRef Medline

Wen L, Tang FL, Hong Y, Luo SW, Wang CL, He W, Shen C, Jung JU, Xiong F, Lee DH, Zhang QG, Brann D, Kim TW, Yan R, Mei L, Xiong WC (2011) VPS35 haploinsufficiency increases Alzheimer's disease neuropathology. J Cell Biol 195:765-779. CrossRef Medline

Yin J, Liu X, He Q, Zhou L, Yuan Z, Zhao S (2016) Vps35-dependent recycling of Trem2 regulates microglial function. Traffic 17:1286-1296. CrossRef Medline

Yoshimi K, Ren YR, Seki T, Yamada M, Ooizumi H, Onodera M, Saito Y,
Murayama S, Okano H, Mizuno Y, Mochizuki H (2005) Possibility for neurogenesis in substantia nigra of parkinsonian brain. Ann Neurol 58: 31-40. CrossRef Medline

Zhang J, Jiao J (2015) Molecular biomarkers for embryonic and adult neural stem cell and neurogenesis. Biomed Res Int 2015:727542. CrossRef Medline

Zhao C, Teng EM, Summers RG Jr, Ming GL, Gage FH (2006) Distinct morphological stages of dentate granule neuron maturation in the adult mouse hippocampus. J Neurosci 26:3-11. CrossRef Medline

Zhao M, Momma S, Delfani K, Carlen M, Cassidy RM, Johansson CB, Brismar H, Shupliakov O, Frisen J, Janson AM (2003) Evidence for neurogenesis in the adult mammalian substantia nigra. Proc Natl Acad Sci U S A 100:7925-7930. CrossRef Medline

Zhu XJ, Wang CZ, Dai PG, Xie Y, Song NN, Liu Y, Du QS, Mei L, Ding YQ, Xiong WC (2007) Myosin X regulates netrin receptors and functions in axonal path-finding. Nat Cell Biol 9:184-192. CrossRef Medline

Ziabreva I, Perry E, Perry R, Minger SL, Ekonomou A, Przyborski S, Ballard C (2006) Altered neurogenesis in Alzheimer's disease. J Psychosom Res 61:311-316. CrossRef Medline 